\title{
Effects of graphene sulfonate nanosheets on mechanical and thermal properties of sacrificial concrete during high temperature exposure
}

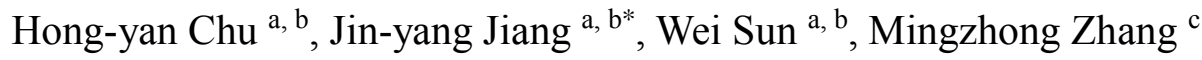

${ }^{a}$ School of Materials Science and Engineering, Southeast University, Nanjing 211189, China

${ }^{b}$ Jiangsu Key Laboratory of Construction Materials, Nanjing 211189, China

${ }^{\mathrm{c}}$ Advanced and Innovative Materials (AIM) Group, Department of Civil, Environmental and Geomatic Engineering, University College London, London WC1E 6BT, UK

\begin{abstract}
Using nanomaterials is a new method to improve concrete material, and graphene or its derivatives are currently the most attractive nanomaterials. This paper aims to experimentally evaluate the effects of graphene sulfonate nanosheets (GSNSs) on physical, mechanical, and thermal properties of sacrificial concrete. The microstructure, porosity, compressive strength, thermal analysis, coefficient of thermal expansion, thermal diffusivity and ablation behaviour of sacrificial concrete with different contents of GSNSs before and during exposure to various temperatures up to $1000{ }^{\circ} \mathrm{C}$ were comprehensively investigated. A new experimental apparatus was proposed and used to measure the compressive strength of sacrificial concrete during elevated temperature exposure. It was found that, (1) the compressive strength, thermal diffusivity, and decomposition enthalpy of sacrificial concrete increased by $10.14-23.11 \%, 6.51-27.66 \%$, and $7.48 \%$, respectively, when adding $0.1 \mathrm{wt} \%$ GSNSs; (2) the porosity and ablation velocity of sacrificial concrete reduced by $2.00-6.00 \%$ and $7.48 \%$, respectively, due to the incorporation of GSNSs.
\end{abstract}

Keywords: sacrificial concrete; graphene sulfonate nanosheets; porosity; compressive strength; coefficient of thermal expansion; thermal diffusivity

\section{Introduction}

Currently, concrete is the most important and widely used construction material. However, concrete is a quasi-brittle material, and is inclined to crack, since it has high compressive strength but relatively low flexural strength [1]. Consequently, to prevent cracking and to improve the strength especially the flexural strength are the essential methods to extend the service life of concrete and concrete structures. Recent progress in the field of nanotechnology has presented an opportunity to enhance the performance of cementitious composites by adding fibres or nano-sized particles, such as nano-

\footnotetext{
* Corresponding author. Tel.: +86-025-52090667; E-mail address: jiangjinyang16@163.com (J.-y. Jiang)
} 
silica [2-5], nano-titanium oxide [6], and carbon nanotubes [7-10]. Nano-sized reinforcements in cementitious composites were found to be more effective than conventional reinforcements that are usually limited at millimeter scale, because nano-sized particles can help control nano-size cracks (at the initial stage) before they extend to micro-size cracks [11]. It has been indicated that the microstructure and strength of hydration gels in cementitious composites can be substantially improved if the used nano-sized materials are properly treated. Furthermore, some nano-sized reinforcements can enhance the packing density of calcium silicate hydrates (C-S-H), thus the porosity can be reduced effectively, as a result of which the transport of aggressive agents into cementitious composites would be slowed down significantly. Therefore, many improvements in the microstructure of concrete can be achieved by incorporating nano-sized materials into concrete.

In recent years, graphene, as a new carbon nanomaterial, has attracted the most attention in science and engineering. Compared with other nanomaterials, graphene demonstrates a unique atom-thick $\mathrm{sp}^{2}$ bonded 2D structure [12]. Graphene has excellent electrical, optical, mechanical, and thermal properties, and its intrinsic tensile strength and Young's modulus are estimated to $130 \mathrm{GPa}$ and $1 \mathrm{TPa}$, respectively [13]. The thermal conductivity of suspended graphene can be as high as $5300 \mathrm{~W} / \mathrm{mK}$ [14]. Moreover, the specific surface area of a single graphene sheet can reach $2630 \mathrm{~m}^{2} / \mathrm{g}$, and the aspect ratio (defines as the ratio of the width to the thickness) of a single graphene sheet is more than 2000 [14]. The great exposed surface areas of graphene are conducive to potential chemical or physical interactions between graphene and matrix material. Accordingly, graphene has a promising application prospect when combined with cementitious composites. However, difficulty in dispersing graphene and high cost of production are the major challenges, which limit the practical utilization of graphene. Graphene nanosheets (GNSs) and graphene oxide nanosheets (GONSs) are new kinds of nano-sized materials consisting of graphene stacks or graphene sheets [15-20]. Both GNSs and GONSs display a 2D sheet-like structure, and the thickness of them is generally less than $10 \mathrm{~nm}$, that is, still at nano scale. Unlike pure graphene, GONSs are oxides of GNSs, and thus contain oxygen functional groups attached on the basal plans and edges of graphene oxide sheets. The functional groups can significantly modify the van der Waals interactions between the GONSs, and therefore can enhance their dispersion in water [21]. In addition, as the derivatives of graphene, the GNSs and GONSs are low-cost nanomaterials.

Up to now, many studies have been carried out to investigate the effects of GNSs or GONSs on 
properties of cementitious materials. The study on the effect of GNSs on the mechanical properties of geopolymer composites by Ranjbar et al. [22] indicated that the compressive strength and flexural strength of geopolymer were improved by 1.44 and 2.16 times, respectively, when adding $1 \mathrm{wt} \%$ GNSs. Lv et al. [23] observed that the tensile, flexural, and compressive strength of cementitious composite could be increased by $78.6 \%, 60.7 \%$, and $38.9 \%$, respectively, if $0.03 \mathrm{wt} \%$ GONSs (with respect to weight of cement) were added. Pan et al. [17] found that the addition of $0.05 \mathrm{wt} \%$ GONSs resulted in the increases in compressive strength and flexural strength of cementitious composite by 15-33\% and 41-59\%, respectively. Lv et al. [24] investigated the effect of GONSs on the microstructure and mechanical properties of cement paste, and observed that GONSs could regulate the cement hydration products and further form ordered microstructure, and the compressive and flexural strength of cement paste increased by $56.6 \%$ and $77.6 \%$, respectively, when adding $0.03 \mathrm{wt} \%$ GONSs. In addition to improving strength, GNSs or GONSs can bring certain self-sensing capability to cementitious materials. Le et al. [19] pointed out that the GNSs can be used to characterize the damage in cementitious composites by measuring the electric potential of specimens. The study found that the GNSs reinforced cementitious composites exhibited the potential of self-sensing to damage throughout the extraordinary electrical conductivity of GNSs. Although GNSs or GONSs have been extensively investigated on cement paste or mortar, their applications in concrete have, to date, remained limited. In addition, there is no published research on the effects of graphene sulfonate nanosheets (GSNSs) on microstructure and properties of cementitious composites.

Sacrificial concrete is designed to reduce the leakage potential of radioactive materials in severe nuclear accidents [25]. On one hand, sacrificial concrete can melt and mix with corium (a molten mixture of fuel material, partially or totally oxidized cladding, non-volatile fission products, and various structural materials), reducing the temperature of corium. On the other hand, the $\mathrm{SiO}_{2}$ from sacrificial concrete can oxidize $\mathrm{Zr}$ in the corium, and the glassily matrix formed by molten $\mathrm{SiO}_{2}$ can enwrap the radioactive fission products [26]. The core technical parameters of sacrificial concrete are as follows, (1) the silica sand should contain $\mathrm{SiO}_{2} \geq 83 \mathrm{wt} \%, \mathrm{CaCO}_{3} \leq 8.5 \mathrm{wt} \%$, and $\mathrm{MgCO}_{3} \leq 1$ $\mathrm{wt} \%$, respectively; (2) in the mixtures of sacrificial concrete, the content of silica sand (including dry parts of admixtures and additives) should reach $85 \%$ of total dry mass of sacrificial concrete; (3) the slump flow is supposed to be in the range of 55 to $65 \mathrm{~cm}$ for fresh sacrificial concrete; (4) after curing, the free water content and compressive strength should be less than 5\%, and more than $30 \mathrm{MPa}$, respectively; (5) when exposed to high temperatures, the sacrificial concrete should guarantee the 
integrity up to $1000^{\circ} \mathrm{C}[25]$.

In the event of fire or nuclear accident, concrete is subjected to high temperature. Although the properties of concrete after high temperature exposure have been extensively studied [27-32], the available information on the thermal properties of sacrificial concrete is rare, and needs to be updated. The damage in concrete induced by elevated temperature is recovered slightly during cooling, so the properties of concrete after high temperature exposure do not represent the actual situation of material at elevated temperature, especially its mechanical properties. Chu et al. [33] have recently presented a comprehensive investigation on thermal behaviour and damage evolution of sacrificial concrete after elevated temperature exposure. However, effects of GSNSs on mechanical and thermal properties of sacrificial concrete have not been studied. A compressive understanding of the mechanical performance of sacrificial concrete during high temperature exposure is crucial to provide a better guidance for design of the material, but there are no published literatures on the mechanical properties of sacrificial concrete during elevated temperature exposure.

This paper, for the first time, investigates the effects of GSNSs on mechanical and thermal properties of sacrificial concrete before and during high temperature exposure. To this end, the microstructure, porosity, compressive strength, thermogravimetric analysis (TGA), differential scanning calorimetry (DSC), coefficient of thermal expansion (CTE), thermal diffusivity, and ablation behaviour of sacrificial concrete with different contents of GSNSs before and during exposure to various temperatures (i.e., 200, 400, 600, 800, and $1000^{\circ} \mathrm{C}$ ) were comprehensively investigated. In addition, a new experimental facility for compressive strength measurement of sacrificial concrete at high temperature was presented.

\section{Materials}

\subsection{Cement and supplementary cementitious materials}

Silica fume and Class I fly ash (equivalent to ASTM C 618 Class F fly ash) were used as supplementary cementitious materials in the study. The silica fume was used to improve the fluidity of fresh sacrificial concrete. The chemical composition and physical properties of cement and supplementary cementitious materials are shown in Table 1 . The compressive strength of cement paste at 28 days was $62.8 \mathrm{MPa}$.

\subsection{Aggregate}


The aggregate used in the paper was silica sand produced by Nuclear Industry Nonmetallic Mineral Powders Co., Ltd (Liuzhou, China). The chemical composition of silica sand was $\mathrm{SiO}_{2}, \mathrm{CaCO}_{3}$, and $\mathrm{MgCO}_{3}$, the weight fractions of which were $99.88 \%, 0.058 \%$, and $0.062 \%$, respectively. Therefore, the chemical composition of the silica sand fulfilled the requirements of sacrificial concrete mentioned above. The sieve analysis of silica sand is shown in Table 2.

\subsection{Superplasticizer}

A superplasticizer of polycarboxylate supplied by Sobute New Materials Co., Ltd (Nanjing, China) was utilized to gain a satisfactory fluidity of sacrificial concrete. The solid content of the superplasticizer was $40.0 \mathrm{wt} \%$.

\subsection{Polypropylene fibre}

In order to enhance the high temperature integrity of sacrificial concrete, the polypropylene fibre was added. The physical and mechanical properties of polypropylene fibre used in the paper are presented in Table 3.

\subsection{Graphene sulfonate nanosheets (GSNSs)}

Graphene sulfonate solution was produced and provided by Graphene-Tech Co., Ltd (Suzhou, China), and its solid content was $10.5 \mathrm{wt} \%$. The particle size and thickness of GSNSs were 50-100 $\mu \mathrm{m}$ and 1-2 $\mathrm{nm}$, respectively.

\subsection{Mix proportions of sacrificial concrete}

The mixtures of sacrificial concrete used in the paper were carefully designed according to our previous research findings, as shown in literature [25]. Based on these results, the mixtures of sacrificial concrete for this work were further improved via the addition of GSNSs, and are shown in Table 4. Note that the content of GSNSs in the SCG mixture was $0.1 \mathrm{wt} \%$ of binders (cement and supplementary cementitious materials).

As shown in Table 4, the slump flow and the dry mass proportion of silica sand (including dry parts of admixtures and additives) were $59 \mathrm{~cm}$ and $85.03 \%$, respectively, both of which met the requirements mentioned above for sacrificial concrete without GSNSs (SC). With regards the sacrificial concrete with GSNSs (SCG) mixture in Table 4, slump flow and the dry mass proportion of silica sand (including dry parts of admixtures and additives) were $56 \mathrm{~cm}$ and $85.03 \%$, respectively, both of which fulfilled the aforementioned requirements for sacrificial concrete as well. 
According to the above mix proportions, the specimens (shape: cubic; size: $150 \times 150 \times 150 \mathrm{~mm}$ ) of sacrificial concrete were cast. After casting, the molds were covered with plastic sheets and cured 24 hours at ambient condition, and then the molds were removed, and the specimens were placed into a concrete curing room for curing over 28 days with a temperature of $21 \pm 1{ }^{\circ} \mathrm{C}$ and relative humidity of above $95 \%$. In total, 80 cubic specimens were prepared for each mix proportion. It should be emphasized that the free water contents of sacrificial concrete without and with GSNSs after curing were $4.09 \%$ (SC) and $4.15 \%$ (SCG), respectively, which suggested that the free water contents of sacrificial concrete used in this work could also meet the requirements mentioned above

\section{Experimental work}

\subsection{Microstructure}

In order to detect the microstructural evolution in sacrificial concrete before and after exposure to elevated temperatures, the microstructural characterisation of sacrificial concrete was undertaken using a FEI 3D environmental scanning electronic microscopy (ESEM), and the micrographs of specimens were taken before and after exposure to high temperatures.

\subsection{Porosity}

A Micromeritics AutoPore IV 9510 mercury intrusion porosimetry (MIP) was used to characterize the pore structure evolution in sacrificial concrete in order to investigate the porosity and pore size distribution of sacrificial concrete before and after exposure to elevated temperatures in a quantitative manner.

\subsection{Compressive strength}

The new experimental facility developed for measurement of compressive strength of sacrificial concrete at elevated temperature is presented in Fig. 1. The new experimental setup consists of a universal testing machine and an electrical furnace. The outline of the universal testing machine is taken as the columns and steel beams in Fig. 1, and the maximum loading of the universal testing machine is $3000 \mathrm{kN}$. In addition, the up and down blocks of the machine are made up of a high temperature resistant material that still has high strength and stiffness at $1200{ }^{\circ} \mathrm{C}$. The red frame in Fig. 1 denotes the electrical furnace. The heating rate and maximum temperature of the furnace are $0.5^{-15}{ }^{\circ} \mathrm{C} / \mathrm{min}$ and $1500{ }^{\circ} \mathrm{C}$, respectively. The furnace is bigger enough to hold 3 padding blocks on the slide rail, and there is an electric actuator to push the padding blocks along the track, thus the compressive strength of 3 specimens can be determined at a time. The silicon carbide rods are 
distributed evenly on the side walls of the furnace, and there is a thermocouple at the middle of the furnace to monitor the temperature of the furnace chamber. In the new experimental facility, there are cooling systems on the up and down blocks of the universal testing machine and the electric actuator, and the cooling is achieved by letting the cool water flow the cooling systems.

In the paper, the specimens were heated from ambient temperature $\left(25^{\circ} \mathrm{C}\right)$ to $200,400,600,800$, and $1000{ }^{\circ} \mathrm{C}$, respectively, at a heating rate of $5^{\circ} \mathrm{C} / \mathrm{min}$. According to literature [27], the specimens were held at the target temperature for 2 hours so as to ensure uniform temperature throughout each specimen. After that, the universal testing machine was used to determine the compressive strength of specimens before and during high temperature exposure at a loading rate of $0.3 \mathrm{MPa} / \mathrm{s}$. In order to obtain the compressive strength of sacrificial concrete after elevated temperature exposure, some other specimens were heated at the same heating rate, and were also held at the target temperature for 2 hours, but they were cooled to ambient temperature in the furnace before they were carried out mechanical tests.

\subsection{Thermal analysis}

In order to study the mass and enthalpy evolution of sacrificial concrete during high temperature exposure, thermal analysis of sacrificial concrete was performed using a simultaneous thermal analyzer (NETZSCH STA449 F3). Both TGA and DSC of sacrificial concrete were carried out in the study. The testing conditions were as follows: heating rate $10{ }^{\circ} \mathrm{C} / \mathrm{min}$, up to $1300{ }^{\circ} \mathrm{C}$, in nitrogen circumstance, at standard atmospheric pressure. The specimens utilized in the experiment were ground by hand using an agate mortar.

\subsection{Coefficient of thermal expansion (CTE)}

A dynamic thermal mechanical analyzer (NETZSCH TMA402 F1) was used to measure the CTE of sacrificial concrete during high temperature exposure. The CTE and thermal strain tests of sacrificial concrete were carried out on $8 \times 8 \times 20 \mathrm{~mm}$ prismatic specimens that were sliced from $150 \times 150 \times 150 \mathrm{~mm}$ specimens, according to the standard ASTM E 831-03. The linear variation in the length of each specimen was measured by the instrument under temperatures from 25 to $1000{ }^{\circ} \mathrm{C}$ at a heating rate of $10^{\circ} \mathrm{C} / \mathrm{min}$. The relationship between thermal strain and linear CTE can be determined using Eqs. (1) and (2), given as follows,

$$
\varepsilon=\Delta L / L_{0}
$$




$$
\Delta L=\alpha \cdot L_{0} \cdot \Delta T
$$

where $\varepsilon$ is the thermal strain, $\alpha$ is the linear CTE, $\Delta L$ is the unit length change, $\Delta T$ is the temperature difference, and $L_{0}$ is the initial length of the specimen.

Substituting Eq. (2) to Eq. (1), the relationship between thermal strain and CTE can be obtained as,

$$
\varepsilon=\alpha \cdot \Delta T
$$

According to Eq. (3), the CTE of sacrificial concrete can be determined at each target temperature. In addition, the CTE was required in order to calculate the volume evolution of sacrificial concrete after exposure to high temperatures.

\subsection{Thermal diffusivity}

Heat transmission through conduction is determined by the thermal diffusivity during steady or quasi-steady conditions. The higher the thermal diffusivity of material has, the lower its insulation capability is. The thermal diffusivity of material, a, is defined as the ratio of the heat transmitted to the heat stored by the unit mass of the material.

$$
\mathrm{a}=\lambda /(c \cdot \rho)
$$

where $\lambda$ is thermal conductivity, $c$ is specific heat, and $\rho$ is density.

The initial density of sacrificial concrete, $\rho_{0}$, can be determined as,

$$
\rho_{0}=m_{0} / V_{0}
$$

where $m_{0}$ is the initial mass, and the $V_{0}$ is the initial volume.

The mass evolution of sacrificial concrete during high temperature exposure was obtained from the TGA experiment, and its volume variation at elevated temperature was gained from the CTE test with the assumption that the sacrificial concrete is a homogeneous material. Therefore, the density of sacrificial concrete during high temperatures $\rho$ can be calculated from the following equation,

$$
\rho=m^{T} / V^{T}=\left[(1-\gamma) m_{0}\right] /\left[(1+\beta) V_{0}\right]=\left[(1-\gamma) \rho_{0}\right] /(1+\beta)
$$

where is $\gamma$ the mass loss ratio, $\beta=3 \alpha$ is volumetric CTE, $m^{T}$ and $V^{T}$ are mass and volume of sacrificial concrete at elevated temperatures, respectively.

A laser thermal constant analyzer (NETZSCH LFA457) was utilized to determine the thermal conductivity and the specific heat of sacrificial concrete before and during high temperature exposure 
$\left(25,200,400,600,800\right.$, and $\left.1000^{\circ} \mathrm{C}\right)$, according to the standard ASTM E 1461-13. The laser flash source was Neodymium-doped gadolinium gallium garnet crystal with a radiant pulse energy up to 18.5 J. The temperature evolution of specimen was detected by an advanced non-contact infrared detector. The specimen size used in the experiment was $10 \times 10 \times 1 \mathrm{~mm}$. Using this laser thermal constant analyzer, the thermal conductivity and specific heat of sacrificial concretes before and during elevated temperatures exposure were measured, and then their thermal diffusivity was calculated using Eq. (4).

\subsection{Ablation behaviour}

According to the theory of heat transfer, the relationship between ablation velocity $v$ of sacrificial concrete and the heat flux $\dot{Q}$ can be expressed as follows,

$$
\mathrm{v}=\dot{Q} /(\rho \cdot A \cdot \Delta H)
$$

where $\rho$ is density, $A$ is ablating area, and $\Delta H$ is decomposition enthalpy of sacrificial concrete.

The enthalpy of sacrificial concrete can be estimated by integrating the DSC curve [34]. Note that the zero point of enthalpy was set to $25^{\circ} \mathrm{C}$ in this work. In addition, the decomposition temperature of sacrificial concrete can be obtained through a computer-controlled radiant electrically furnace with the heating rate of $5^{\circ} \mathrm{C} / \mathrm{min}$, and its decomposition enthalpy can be subsequently determined. As such, a qualitative analysis of the ablation velocity of sacrificial concrete can be carried out.

It should be pointed out that 3 replicated measurements were tested at each target temperature on the porosity, compressive strength, TGA, DSC, CTE, and thermal diffusivity experiments so as to improve the accuracy of experimental results. Only the average values were reported herein.

\section{Results and discussion}

\subsection{Microstructure}

ESEM results illustrated distinct variations in the microstructure of sacrificial concrete at both ambient and high temperatures. Fig. 2 presents the ESEM micrographs of specimens before and after exposure to $200,400,600,800$, and $1000{ }^{\circ} \mathrm{C}$.

The matrix of sacrificial concrete without GSNSs displayed a continuous microstructure without micro cracks at ambient temperature, as illustrated in Fig. 2a. A small number of micro cracks were detected at 200 and $400{ }^{\circ} \mathrm{C}$, while a fairly large number of micro cracks emerged with the temperature up to $600{ }^{\circ} \mathrm{C}$. In addition, there were 2 channels left by molten polypropylene fibres at 400 and 600 
${ }^{\circ} \mathrm{C}$, and some micro cracks were also observed in the aggregate at $600{ }^{\circ} \mathrm{C}$. At $800{ }^{\circ} \mathrm{C}$, connected cracks spread all over the specimen. After exposure to $1000{ }^{\circ} \mathrm{C}$, the matrix of sacrificial concrete without GSNSs became amorphous structure, and the micro cracks widened. With the increase of temperature, the matrix evolution of sacrificial concrete with GSNSs was similar to that of sacrificial concrete without GSNSs, as shown in Fig. 2b. However, the matrix of sacrificial concrete with GSNSs was more compact than that of sacrificial concrete without GSNSs at $25^{\circ} \mathrm{C}$. The microstructure evolution of sacrificial concrete without and with GSNSs was similar to that of siliceous sacrificial concrete subjected to elevated temperatures [33]. Both cement paste and aggregate in sacrificial concrete were affected by high temperature, resulting from pressure build-up due to moistures [35] and carbon dioxide release [33], and from thermal stress due to thermal gradient [36] or thermal incompatibility [37]. The damaged microstructure led to the deterioration of sacrificial concrete.

In addition, ESEM studies indicated that GSNSs had reinforcing and toughing effects on the pore structure of sacrificial concrete, as illustrated in Fig. 3. It should be mentioned that the blue square in Fig. 3a was enlarged to show details which were shown in Fig. 3b. The cumulate plate-shaped products (Fig. 3b) were observed at the place of a pore, which could have reinforcing and toughing effects on the pore structure, and thus enhance the microstructure of sacrificial concrete. The energy dispersive spectrometer (EDS) analysis was performed on the blue square in Fig. $3 \mathrm{~b}$ and showed that the main elemental compositions of this area were C, O, Ca, S, and Fe with weight percentages of $45.36 \%, 32.63 \%, 11.58 \%, 5.07 \%$, and $3.16 \%$, respectively. These results revealed that the cumulate plate-shaped products formed were due to the added GSNSs, because the sulfonic groups in GSNSs might react with hydration products to form covalent bonds, which was similar to poly methyl methacrylate in graphene sheets [38]. Consequently, the GSNSs could improve the microstructure of sacrificial concrete because of their reinforcing and toughing effects on the pore structure.

\subsection{Porosity}

The porosity and pore size distribution of sacrificial concrete at ambient temperature $\left(25^{\circ} \mathrm{C}\right)$ and after heating to $200,400,600,800$, and $1000^{\circ} \mathrm{C}$ are shown in Fig. 4.

The porosity of sacrificial concrete increased continually with the increase of temperature, which was in good agreement with that of the high-strength concrete exposure to high temperatures [39]. As shown in Fig. $4 \mathrm{a}$, the porosity increased slowly in the range of $25-400{ }^{\circ} \mathrm{C}$, while the porosity increased rapidly during $400-800{ }^{\circ} \mathrm{C}$, the result of which was consistent with the increasing cracks in the 
microstructures (see Fig.2) of sacrificial concrete during the same temperature range. After that, there was a slow growth in the porosity of sacrificial concrete between 800 and $1000{ }^{\circ} \mathrm{C}$. In the whole range of $25-1000{ }^{\circ} \mathrm{C}$, the porosity increasing amplitudes of sacrificial concrete without and with GSNSs were $292.83 \%$ (SC) and $301.09 \%$ (SCG), respectively. The increase in porosity can be attributed to the loss of water in capillary pores and hydration products [40], and cracks due to incompatible deformation between cement paste and aggregate [37], and the channels left by the molten polypropylene fibres (see Fig.2).

In addition, the porosity of sacrificial concrete with GSNSs was invariably lower than that of sacrificial concrete without GSNSs during $25-1000{ }^{\circ} \mathrm{C}$, and the porosity of sacrificial concrete reduced by $2.00-6.00 \%$ due to the incorporation of GSNSs. On one hand, the GSNSs could improve the microstructure of sacrificial concrete by their reinforcing and toughing effects on the pore structure, which led to the decrease in overall porosity. On the other hand, the thermal gradient [36] in sacrificial concrete with GSNSs was lower than that of sacrificial concrete without GSNSs due to the addition of GSNSs, as a result of which the thermal damage induced in the former was lower than that of the latter. Accordingly, the porosity increasing amplitudes for sacrificial concrete with GSNSs were lower than those of sacrificial concrete without GSNSs when sacrificial concrete was subjected to elevated temperatures.

Regarding pore size distribution, there were multiple peaks when the temperature is within the range of $25-1000{ }^{\circ} \mathrm{C}$, and the threshold pore diameter increased with the increase of temperature (see Fig.4b, c). For sacrificial concrete without GSNSs (see Fig.4b), most of pore sizes at 25, 400, and $800{ }^{\circ} \mathrm{C}$ were within two peaks interval $(0.008,0.08),(0.03,1.68)$, and $(0.13,32.99)$, respectively, all in $\mu \mathrm{m}$. A similar trend was observed in sacrificial concrete with GSNSs (see Fig.4c), but to a smaller degree, from $0.007-0.07 \mu \mathrm{m}$ at $25{ }^{\circ} \mathrm{C}$, to $0.03-1.57 \mu \mathrm{m}$ at $400{ }^{\circ} \mathrm{C}$, to $0.12-32.62 \mu \mathrm{m}$ at $800{ }^{\circ} \mathrm{C}$. These results could explain why the porosity of sacrificial concrete increased slowly in the range of $25-400{ }^{\circ} \mathrm{C}$, while the porosity increased sharply between 400 and $800^{\circ} \mathrm{C}$.

\subsection{Residual compressive strength}

Fig. 5 illustrates the residual compressive strength and the relative residual compressive of sacrificial concrete both at ambient and elevated temperatures. It should be noted that the relative compressive strength is defined as the ratio of residual compressive strength at high temperature to compressive strength at ambient temperature $\left(25^{\circ} \mathrm{C}\right)$. 
With the increase of temperature, the compressive strength of sacrificial concrete decreased monotonically, as shown in Fig.5a, which is in line with that of high performance self-compacting concrete [41], ultra-high strength concrete [42], and ferro-siliceous concrete [25] exposed to high temperatures. During the whole compressive strength test $\left(25-1000{ }^{\circ} \mathrm{C}\right)$, no spalling was observed for all the specimens of sacrificial concrete, which suggested that the sacrificial concrete remained integrated up to $1000{ }^{\circ} \mathrm{C}$, and could meet the above-mentioned requirements for sacrificial concrete. The compressive strength of sacrificial concrete without and with GSNSs was $57.78 \mathrm{MPa}$ (SC) and 63.64 MPa (SCG) after curing, respectively, both of which were much higher than the required 30 MPa. The decrease of compressive strength could be explained by the corresponding increasing porosity of sacrificial concrete (see Fig.4a). In addition, the compressive strength of sacrificial concrete with GSNSs was always higher than that of sacrificial concrete without GSNSs in the range of $25-1000{ }^{\circ} \mathrm{C}$, and the compressive strength of sacrificial concrete increased by $10.14-23.11 \%$ due to the incorporation of GSNSs. Owing to the reinforcing effects of GSNSs, the compressive strength of sacrificial concrete with GSNSs was higher than that of sacrificial concrete without GSNSs at ambient temperature. The thermal damage induced in the former was lower than that of the latter at elevated temperatures, because the thermal gradient in sacrificial concrete with GSNSs was lower than that of sacrificial concrete without GSNSs due to the addition of GSNSs. Therefore, the compressive strength decreasing amplitude for sacrificial concrete with GSNSs was lower than that of sacrificial concrete without GSNSs during high temperature exposure. Accordingly, the compressive strength of sacrificial concrete with GSNSs was always higher than that of sacrificial concrete without GSNSs when exposed to temperatures ranging $25-1000{ }^{\circ} \mathrm{C}$.

As illustrated in Fig.5b, the changing trends of relative residual compressive strength of sacrificial concrete without and with GSNSs were consistent with those of their residual compressive strength. In addition, the relative residual compressive strength of sacrificial concrete with GSNSs was always higher than that of sacrificial concrete without GSNSs at each temperature, which gave indirect evidence to the finding that thermal damage induced in the former was lower than that of the latter at elevated temperatures. The relative residual compressive strength of sacrificial concrete did not change significantly at $200{ }^{\circ} \mathrm{C}$, at which the relative residual compressive strength of sacrificial concrete without and with GSNSs was $89.14 \%$ (SC) and 90.21\% (SCG), respectively. Nevertheless, there was a sharp drop in relative residual compressive strength when temperature changed from 400 to $600{ }^{\circ} \mathrm{C}$, and the relative residual compressive strength was only $39.68 \%$ (SC) and $41.29 \%$ (SCG) 
at $600{ }^{\circ} \mathrm{C}$. Moreover, it decreased slowly during $800-1000{ }^{\circ} \mathrm{C}$, but the relative residual compressive strength was merely $17.82 \%$ (SC) and $19.93 \%$ (SCG) at $1000{ }^{\circ} \mathrm{C}$. Hence, the critical temperature of sacrificial concrete was $400-600{ }^{\circ} \mathrm{C}$, in which its compressive strength decreased dramatically. It should be mentioned that the friction effects (between the press platens and the specimen) might result in the decrease in residual compressive strength of sacrificial concretes [43].

Furthermore, a comparative study on the residual compressive strength of sacrificial concrete during and after exposure to high temperatures was carried out in this work, and the results are shown in Fig. 6. The compressive strength of sacrificial concrete without and with GSNSs during high temperatures exposure was always lower than that of sacrificial concrete without and with GSNSs after exposure to elevated temperatures, respectively, as illustrated in Fig. 6, and the former was 4.23$8.59 \%$ (SC) and 4.02-7.99\% (SCG), lower than that of the latter, respectively. These findings suggested that the damage induced by high temperature in sacrificial concrete was recovered slightly during cooling, and the compressive strength after elevated temperature exposure could not represent the actual situation of sacrificial concrete during high temperature exposure. Consequently, the compressive strength obtained in the paper could provide a better guidance for strength design of sacrificial concrete.

\subsection{Thermal analysis}

The effects of temperature on thermal decomposition (TGA) and heat absorption/desorption (DSC) of sacrificial concrete are presented in Fig. 7.

As seen in Fig. 7a, with the increase of temperature, the weight evolution of sacrificial concrete without and with GSNSs was similar, because the mix proportions (see Table 4) of them were nearly the same. A quick weight loss was observed in the TGA between 25 and $150{ }^{\circ} \mathrm{C}$, the result of which was in accordance with that of self-compacting cement paste subjected to high temperatures [44]. The weight loss can be attributed to the loss of evaporable water and part of physically bound water in sacrificial concrete. In the range of $105-700{ }^{\circ} \mathrm{C}$, the mass loss indicated from TGA related to the loss of chemically bound water and the dehydration products [45]. There was a significant loss in the weight of sacrificial concrete at approximately $700{ }^{\circ} \mathrm{C}$, which can be explained by the decarbonation of calcium carbonate. After that temperature, the curves of TGA changed smoothly. Another quick drop in the weight of sacrificial concrete was observed at about $1200^{\circ} \mathrm{C}$, due to the melting of Portland cement. In addition, the weight loss of sacrificial concrete without GSNSs was higher than that of 
sacrificial concrete with GSNSs in the range of $25-650^{\circ} \mathrm{C}$, while a contrary tendency was presented above $650{ }^{\circ} \mathrm{C}$. The total weight loss of sacrificial concrete without and with GSNSs up to $1300{ }^{\circ} \mathrm{C}$ was $6.02 \%(\mathrm{SC})$ and $5.80 \%(\mathrm{SCG})$, respectively.

Similar to the TGA curves, the DSC patterns of sacrificial concrete without and with GSNSs were also close, as shown in Fig. $7 \mathrm{~b}$, because the hydration products of them were basically the same. The dehydration of sacrificial concrete took place at about $100{ }^{\circ} \mathrm{C}$ characterized by loss of evaporable water and part of physically bound water, which is accordance with the observation by Bazant and Kaplan [45]. In the range of $400-600^{\circ} \mathrm{C}$, the decomposition of $\mathrm{CH}$ occurred, which is consistent with the literature [45]. At about $580^{\circ} \mathrm{C}$, the crystalline of quartz transformed from $\beta$ to $\alpha$ quartz, which is in line with the findings of Chase [34]. The decarbonation of calcium carbonate arose at approximately $700{ }^{\circ} \mathrm{C}$, which is in good agreement with the conclusion that the decomposition of calcium carbonate occurs in the range of $600-900^{\circ} \mathrm{C}$ drawn by Bazant and Kaplan [45]. The melting of Portland cement was detected at about $1200^{\circ} \mathrm{C}$ in the study, and this is consistent with experimental result of reference [34]. It should be emphasized that, in general, the dehydration of hydration products was an ongoing process between 100 and $850{ }^{\circ} \mathrm{C}$.

\subsection{Coefficient of thermal expansion}

Fig. 8 shows the thermal strain of sacrificial concrete. Along with the increase of temperature, the thermal strain of sacrificial concrete was increased continually, as illustrated in Fig.8. Furthermore, the thermal strain increased considerably in the range of $25-600^{\circ} \mathrm{C}$, but the thermal strain increased slightly after $600{ }^{\circ} \mathrm{C}$. Loss of water in hydration products may lead to shrinkage of concrete [46]. However, siliceous aggregate containing quartz can cause inner expansive force in concrete at about $580{ }^{\circ} \mathrm{C}$, because the transformation of quartz from $\beta$ to $\alpha$ form (see Fig.7b) is associated with volumetric expansion. Therefore, the mechanical properties of concrete may degrade under these circumstances [40]. This transformation was also observed in the study, and the thermal strain increased suddenly between 580 and $600{ }^{\circ} \mathrm{C}$ (see Fig.8) for sacrificial concrete without and with GSNSs. The thermal strain of sacrificial concrete without GSNSs was higher than that of sacrificial concrete with GSNSs in the range of $25-1000{ }^{\circ} \mathrm{C}$. This can be explained by the fact that the thermal gradient and thermal damage induced by high temperature in the latter were lower than that of the

former due to the addition of GSNSs. Moreover, the thermal strain of sacrificial concrete without and with GSNSs at $600{ }^{\circ} \mathrm{C}$ was about $15.56 \times 10^{-3}$ (SC) and $14.76 \times 10^{-3}(\mathrm{SCG})$, respectively. 
The phase change on the specimen at elevated temperatures can be characterized by its first derivation of the thermal strain curve. Fig.9 presents the phase change of sacrificial concrete during exposure to high temperatures. The first trough was observed in the figure at approximately $170{ }^{\circ} \mathrm{C}$, since the polypropylene fibres added to sacrificial concrete melt at this temperature. There were two obvious peaks in the curves at about $580{ }^{\circ} \mathrm{C}$, due to the transformation of quartz from $\beta$ to $\alpha$, the result of which was accordance with DSC experiment (see Fig.7b). The next weak trough occurred at around $900{ }^{\circ} \mathrm{C}$, because free $\mathrm{CH}$ turns into $\mathrm{CaO}$.

Based on Eq. (3), the CTE of sacrificial concrete could be obtained, the results of which are shown in Fig. 10. The CTE evolution of sacrificial concrete without and with GSNSs was close, which was in consistent with the results of their thermal strain (see Fig.8). In the range of $25-150{ }^{\circ} \mathrm{C}$, a rapid increase in the CTE of sacrificial concrete was observed, but it slightly dropped between 150 and 200 ${ }^{\circ} \mathrm{C}$ due to the evaporation of internal free water in $\mathrm{C}-\mathrm{S}-\mathrm{H}$ gel [47]. After that, the CTE increased continually and then decreased, and the CTE reached the maximum at approximately $600{ }^{\circ} \mathrm{C}$. In the range of $250-500{ }^{\circ} \mathrm{C}$, the decomposition of C-S-H gel led to an increase of CTE. With the increase of temperature, the water evaporated from sacrificial concrete, which resulted in the shrinkage of matrix. Accordingly, the CTE of sacrificial concrete decreased. However, the CTE of sacrificial concretes increased significantly between 550 and $600{ }^{\circ} \mathrm{C}$ because of the transformation of quartz at about 580 ${ }^{\circ} \mathrm{C}$ (see Figs. $7 \mathrm{~b}$ and 9). After $600{ }^{\circ} \mathrm{C}$, the CTE of sacrificial concrete without and with GSNSs reduced gradually. The CTE of sacrificial concrete was about between $1.00 \times 10^{-5}$ and $2.75 \times 10^{-5} 1 /{ }^{\circ} \mathrm{C}$, the result of which higher to that of self-consolidating concrete subjected to high temperatures [47].

In addition, the CTE of sacrificial concrete with GSNSs was always lower than that of sacrificial concrete without GSNSs after $600{ }^{\circ} \mathrm{C}$, which revealed that the CTE of sacrificial concrete could be reduced by adding of GSNSs. This was because the thermal gradient and thermal damage of sacrificial concrete could be mitigated due to the high thermal conductivity of graphene and its derivatives [14]. The CTE of sacrificial concrete did not decline suddenly at high temperatures, which is different from that of self-consolidating concrete (as indicated in [47]). These findings indicated that the integrity of sacrificial concrete subjected to elevated temperature was higher than that of self-consolidating concrete. Furthermore, the high temperature integrity of sacrificial concrete with GSNSs was higher than that of sacrificial concrete without GSNSs above $600{ }^{\circ} \mathrm{C}$. Therefore, the high temperature integrity of sacrificial concrete could be improved because of the addition of GSNSs. 


\subsection{Density}

According to the results of TGA and CTE, the mass loss ratio and volumetric CTE of sacrificial concrete can be calculated, which are presented in Table 5. Based on Eq. (6), the density of sacrificial concrete at elevated temperatures can be calculated precisely by taking its mass loss and volume change into account. The density evolution of sacrificial concrete is illustrated in Fig.11.

As shown in Fig.11, the density evolution of sacrificial concrete without and with GSNSs was very close, which was similar to their weight evolution (see Fig. $7 \mathrm{a}$ ). In the range of $25-200{ }^{\circ} \mathrm{C}$, the decrease of density was significant that corresponds to nearly half of the total density loss. The density declined monotonically between 400 and $600{ }^{\circ} \mathrm{C}$, but less than that of during $25-200{ }^{\circ} \mathrm{C}$, and the density decreased slowly in the range of $800-1000^{\circ} \mathrm{C}$. The density evolution of sacrificial concrete without and with GSNSs is highly related with the weight loss of them (see Fig.7a), the result of which is similar to that of lightweight concrete subjected to high temperatures [48], although its volume variation due to high temperature has not been taken into account in that study. In addition, the density of sacrificial concrete without and with GSNSs was important input data for the calculation of the thermal diffusivity.

\subsection{Thermal diffusivity}

The thermal conductivity and the specific heat of sacrificial concrete both at ambient and high temperatures were determined simultaneously by the laser thermal constant analyzer, the results of which are presented in Table 6 . Furthermore, the density of sacrificial concrete at ambient and each target temperature could be obtained from Fig.11. According to these results, the thermal diffusivity of sacrificial concrete can be calculated via Eq. (4). The thermal diffusivity of sacrificial concrete before and during elevated temperatures exposure is also shown in Table 6, and is presented in detail in Fig. 12.

With the increase of temperature, the thermal diffusivity of sacrificial concrete first decreased and then increased, and reached the minimum at $600{ }^{\circ} \mathrm{C}$, as illustrated in Fig. 12. The changing trend of thermal diffusivity obtained in the range of $25-600{ }^{\circ} \mathrm{C}$ is consistent with that of previous study [33], although the maximum measuring temperature is $600{ }^{\circ} \mathrm{C}$ in that study. In general, the thermal diffusivity of sacrificial concrete ranged from 0.47 to $1.80 \mathrm{~mm}^{2} / \mathrm{s}$ between 25 and $1000{ }^{\circ} \mathrm{C}$. In addition, the thermal diffusivity of sacrificial concrete with GSNSs was always higher than that of sacrificial concrete without GSNSs in the range of $25-1000^{\circ} \mathrm{C}$, and the thermal diffusivity of sacrificial concrete 
could increase by $6.51-27.66 \%$ due to the addition of GSNSs. Consequently, the thermal diffusivity of sacrificial concrete was improved by the incorporation of GSNSs. Furthermore, the higher thermal diffusivity of sacrificial concrete contributed to the decrease in its thermal gradient, and then can further reduce its thermal damage induced at high temperatures. That was why the residual compressive strength of sacrificial concrete with GSNSs was higher than that of sacrificial concrete without GSNSs in the whole range of $25-1000{ }^{\circ} \mathrm{C}$ (see Fig.5a).

The decrease in thermal diffusivity in the range of $25-600{ }^{\circ} \mathrm{C}$ is due to the evaporation of water, the decomposition of hydration productions, and the thermal cracks induced by high temperatures, which have been extensively addressed by other researchers $[33,45,49]$. However, the microstructure (see Fig. 2) of sacrificial concrete was further deteriorated, and the porosity (see Fig.4a) and damage induced were further increased after $600{ }^{\circ} \mathrm{C}$, which eventually led to the increase of thermal conductivity and specific heat, and the decrease of density. However, the increasing amplitude of thermal conductivity was higher than that of specific heat (see Table 6). Hence, the thermal diffusivity of sacrificial concrete tended to increase between 600 and $1000{ }^{\circ} \mathrm{C}$.

\subsection{Ablation behaviour}

According to high temperature experiment by the electrically furnace, the decomposition temperature of sacrificial concrete was approximately $1160{ }^{\circ} \mathrm{C}$. The enthalpy of sacrificial concrete can be obtained from DSC analysis (see Fig. 7b), and is presented in Fig.13.

As shown in Fig.13, the enthalpy of sacrificial concrete increased gradually before a sharp rise. The enthalpy of sacrificial concrete without GSNSs was higher than that of sacrificial concrete with GSNSs between 25 and $750{ }^{\circ} \mathrm{C}$, while a contrary tendency was observed after $750{ }^{\circ} \mathrm{C}$. The decomposition enthalpy of sacrificial concrete without and with GSNSs was $570.06 \mathrm{~kJ} / \mathrm{kg}$ (SC) and $612.69 \mathrm{~kJ} / \mathrm{kg}$ (SCG), respectively, and the latter was 7.48\% higher than that of the former. As shown in Eq. (7), the ablation velocity is directly proportional to the heat flux, but inversely proportional to the density, ablating area, and decomposition enthalpy. The ablation velocity of sacrificial concrete with GSNSs was lower than that of sacrificial concrete without GSNSs on the condition of identical heat flux and ablating area, because the density (see Fig. 11) and decomposition enthalpy (see Fig.13) of the former were always higher than those of the latter. According to the Eq. (7), the ablation velocity of sacrificial concrete reduced by $6.96 \%$ due to the incorporation of GSNSs. Therefore, the melt-through time of basemat should be extended, and then the safety of nuclear power plant could 
be improved in severe nuclear accident. That is, the safety of nuclear power plant could be enhanced by adding of GSNSs to sacrificial concrete.

In summary, compared to the sacrificial concrete without GSNSs, the sacrificial concrete with GSNSs was shown to have more compact matrix, lower porosity, higher residual compressive strength, similar thermal strain and CTE, higher thermal diffusivity and decomposition enthalpy, and lower ablation velocity. The addition of GSNSs to sacrificial concrete could improve its many properties, and enhance the security of nuclear power plant in severe nuclear accident.

\section{Conclusions}

In the paper, the effects of GSNSs on physical, mechanical, and thermal properties of sacrificial concrete are evaluated, and a new experimental facility for compressive strength measurement of sacrificial concrete at high temperature is presented. The main conclusions are drawn as follows,

1) The GSNSs can improve the microstructure of sacrificial concrete by their reinforcing and toughing effects on the pore structure.

2) The porosity of sacrificial concrete increases continually with the increase of temperature. The porosity of sacrificial concrete with GSNSs is invariably lower than that of sacrificial concrete without GSNSs during $25-1000^{\circ} \mathrm{C}$, and the porosity of sacrificial concrete can reduce by 2.00 $6.00 \%$ due to the incorporation of GSNSs. In the whole range of $25-1000{ }^{\circ} \mathrm{C}$, the porosity increasing amplitudes of sacrificial concrete without and with GSNSs are 292.83\% and 301.09\%, respectively.

3) With the increase of temperature, the compressive strength of sacrificial concrete decreases monotonically. The compressive strength of sacrificial concrete with GSNSs is always higher than that of sacrificial concrete without GSNSs in the range of $25-1000^{\circ} \mathrm{C}$, and the compressive strength of sacrificial concrete can increase by $10.14-23.11 \%$ due to the addition of GSNSs.

4) The compressive strength of sacrificial concrete without and with GSNSs during high temperatures exposure is always lower than that of sacrificial concrete without and with GSNSs after exposure to elevated temperatures, respectively, and the former is $4.23-8.59 \%$ and $4.02-$ $7.99 \%$, lower than that of the latter, respectively.

5) With the increase of temperature, the weight evolution of sacrificial concrete without and with GSNSs is similar, and the weight loss of sacrificial concrete without GSNSs is higher than that 
of sacrificial concrete with GSNSs in the range of $25-650^{\circ} \mathrm{C}$, while a contrary tendency is presented above $650^{\circ} \mathrm{C}$. The total weight loss of sacrificial concrete without and with GSNSs up to $1300{ }^{\circ} \mathrm{C}$ is $6.02 \%$ and $5.80 \%$, respectively.

6) Along with the increase of temperature, the thermal strain of sacrificial concrete is increased continually. And the thermal strain increases considerably in the range of $25-600{ }^{\circ} \mathrm{C}$, but the thermal strain increases slightly after $600{ }^{\circ} \mathrm{C}$. The thermal strain of sacrificial concrete without and with GSNSs at $600{ }^{\circ} \mathrm{C}$ is about $15.56 \times 10^{-3}$ and $14.76 \times 10^{-3}$, respectively.

7) The CTE evolution of sacrificial concrete without and with GSNSs is close, which is in line with the results of their thermal strain. The CTE of sacrificial concrete is about between $1.00 \times 10^{-5}$ and $2.75 \times 10^{-5} 1 /{ }^{\circ} \mathrm{C}$. The CTE of sacrificial concrete with GSNSs is always lower than that of sacrificial concrete without GSNSs after $600{ }^{\circ} \mathrm{C}$, which reveals that the CTE of sacrificial concrete can be reduced by adding of GSNSs.

8) The high temperature integrity of sacrificial concrete with GSNSs is higher than that of sacrificial concrete without GSNSs above $600^{\circ} \mathrm{C}$. The high temperature integrity of sacrificial concrete can be improved due to the addition of GSNSs.

9) With the increase of temperature, the thermal diffusivity of sacrificial concrete first decreases and then increases, and reaches the minimum at $600{ }^{\circ} \mathrm{C}$. In general, the thermal diffusivity of sacrificial concrete ranges from 0.47 to $1.80 \mathrm{~mm}^{2} / \mathrm{s}$ between 25 and $1000{ }^{\circ} \mathrm{C}$. The thermal diffusivity of sacrificial concrete with GSNSs is always higher than that of sacrificial concrete without GSNSs in the range of $25-1000^{\circ} \mathrm{C}$, and the thermal diffusivity of sacrificial concrete can increase by $6.51-27.66 \%$ due to the addition of GSNSs. The thermal diffusivity of sacrificial concrete can be improved by the incorporation of GSNSs.

10) The decomposition enthalpy of sacrificial concrete without and with GSNSs is 570.06 and 612.69 $\mathrm{kJ} / \mathrm{kg}$, respectively, and the latter is $7.48 \%$ higher than that of the former, and thus the ablation velocity of the latter is lower than that of the former on the condition of identical heat flux and ablating area. The ablation velocity of sacrificial concrete can reduce by $6.96 \%$ due to the incorporation of GSNSs, and then the safety of nuclear power plant can be improved in severe nuclear accident.

\section{Acknowledgements}

The research is finically supported by National Natural Science Foundation of China (No. 
51378114, and 51611130205), Ministry of Science and Technology of China (973 program, 2015CB655105), and Transformation of Major Scientific, Technological Achievements of Jiangsu Province (No. 85120000220), and The Royal Society (IE150587), which are gratefully acknowledged. The authors also would like to thank Professor Hai-tang Zhu (Zhengzhou University) for his help with mechanical experiments.

\section{References}

[1] V.S. Gopalaratnam, R. Gettu, On the characterization of flexural toughness in fiber reinforced concretes, Cem. Concr. Compos. 17 (1995) 239-254.

[2] C. Nunes, Z. Slizkova, M. Stefanidou, J. Nemecek, Microstructure of lime and lime-pozzolana pastes with nanosilica, Cem. Concr. Res. 83 (2016) 152-163.

[3] M. Nili, A. Ehsani, Investigating the effect of the cement paste and transition zone on strength development of concrete containing nanosilica and silica fume, Mater. Des. 75 (2015) 174-183.

[4] W. Li, Z. Huang, F. Cao, Z. Sun, S. P. Shah, Effects of nano-silica and nano-limestone on flowability and mechanical properties of ultra-high-performance concrete matrix, Constr. Build. Mater. 95 (2015) 366-374.

[5] E. Ghafari, H. Costa, E. Julio, A. Portufal, L. Duraes, The effect of nanosilica addition on flowability, strength and transport properties of ultra high performance concrete, Mater. Des. 59 (2014) $1-9$.

[6] T. Menga, Y. Yub, X. Qiana, S. Zhana, K. Qiana, Effect of nano- $\mathrm{TiO}_{2}$ on the mechanical properties of cement mortar, Constr. Build. Mater. 29 (2012) 241-245.

[7] A.D’Alessandro, M. Rallini, F. Ubertini, A.L. Materazzi, J. M. Kenny, Investigation on scalable fabrication procedures for self-sensing carbon nanotube cement-matrix composites for SHM applications, Cem. Concr. Compos. 65 (2016) 200-213.

[8] S. Parveen, S. Rana, R. Fangueiro, M.C. Paiva, Microstructure and mechanical properties of carbon nanotube reinforced cementitious composites developed using a novel dispersion technique, Cem. Concr. Res. 73 (2015) 215-227.

[9] P. stynoski, P. Mondal, C. Marsh, Effects of silica additives on fracture properties of carbon nanotube and carbon fiber reinforced Portland cement mortar, Cem. Concr. Compos. 55 (2015) 232-240.

[10] S. Xu, J. Liu, Q. Li, Mechanical properties and microstructure of multi-walled carbon nanotubereinforced cement paste, Constr. Build. Mater. 76 (2015) 16-23. 
[11] M.S. Konsta-Gdoutos, Z.S. Metaxa, S.P. Shah, Multi-scale mechanical and fracture characteristics and early-age strain capacity of high performance carbon nanotube/cement nanocomposites, Cem. Concr. Compos. 32(2) (2010) 110-115.

[12] K.S. Novoselov, A.K. Geim, S.V. Morozov, D. Jiang, M. Katsnelson, I. Grigorieva, A. Firsov, Two-dimensional gas of massless Dirac fermions in graphene, Nature 438 (7065) (2005) 197 200.

[13] W. Lv, Z. Li, Y. Deng, Q. Yang, F. Kang, Graphene-based materials for electrochemical energy storage devices: Opportunities and challenges, Energy Storage Mater. 2 (2016) 107-138.

[14] A.K. Geim, K.S. Novoselov, The rise of graphene, Nat. Mater. 6 (2007) 183-191.

[15] T. Kuilla, S. Bhadra, D. Yao, N.H. Kim, S. Bose, J.H. Lee, Recent advances in graphene based polymer composites, Prog. Polym. Sci. 35 (11) (2010) 1350-1375.

[16] C. Soldano, A. Mahmood, E. Dujardin, Production, properties and potential of graphene, Carbon 48 (8) (2010) 2127-2150.

[17] Z. Pan, L. He, L. Qiu, A.H. Korayem, G. Li, J.W. Zhu, F. Collins, D. Li, W.H. Duan, M.C. Wang, Mechanical properties and microstructure of a graphene oxide-cement composite, Cem. Concr. Compos. 58 (2015) 140-147.

[18] V. Chabot, D. Higgins, A. Yu, X. Xiao, Z. Chen, J. Zhang, A review of graphene and graphene oxide sponge: material synthesis and applications to energy and the environment, Energy Environ. Sci. 7 (5) (2014) 1564-1596.

[19] J.L. Le, H. Du, S.D. Pang, Use of 2D graphene nanoplatelets (GNP) in cement composites for structural health evaluation, Compos. Part B 67 (2014) 555-563.

[20] Y. Zhu, S. Murali, W. Cai, X. Li, J.W. Suk, J.R. Potts, R.S. Ruoff, Graphene and graphene oxide: synthesis, properties, and applications, Adv. Mater. 22 (35) (2010) 3906-3924.

[21] J. Kim, L.J. Cote, F. Kim, W. Yuan, K.R. Shull, J. Huang, Graphene oxide sheets at inerfaces, J. Am. Chem. Soc. 132 (23) (2010) 8180-8186.

[22] N. Ranjbar, M. Mehrali, M. Mehrali, U.J. Alengaram, M.Z. Jumaat, Graphene nanoplatelet-fly ash based geopolymer composites, Cem. Concr. Res. 76 (2015) 222-231.

[23] S. Lv, Y. Ma, C. Qiu, T. Sun, J. Liu, Q. Zhou, Effect of graphene oxide nanosheets of microstructure and mechanical properties of cement composites, Constr. Build. Mater. 49 (2013) 121-127.

[24] S. Lv, L. Deng, W. Yang, Q. Zhou, Y. Cui, Fabrication of polycarboxylate/graphene oxide 
nanosheet composites by copolymerization for reinforcing and toughening cement composites, Cem. Concr. Compos. 66 (2016) 1-9.

[25] H. Chu, J. Jiang, W. Sun, M. Zhang, Mechanical and physicochemical properties of ferrosiliceous concrete subjected to elevated temperatures, Constr. Build. Mater. 122 (2016) 743-752.

[26] R.J.M. Konings, T.R. Allen, R.E. Stoller, S. Yamanaka, Comprehensive nuclear materials. Amsterdam: Elsevier. 2012.

[27] Z. Pan, J.G. Sanjayan, F. Collins, Effect of transient creep on compressive strength of geopolymer concrete for elevated temperature exposure, Cem. Concr. Res. 56 (2014) 182-189.

[28] F.L. Monte, P.G. Gambarova, Thermo-mechanical behavior of baritic concrete exposed to high temperature, Cem. Concr. Compos. 53 (2014) 305-315.

[29] S.C. Kou, C.S. Poon, M. Etxeberria, Residue strength, water absorption and pore size distributions of recycled aggregate concrete after exposure to elevated temperatures, Cem. Concr. Compos. 53 (2014) 73-82.

[30] S.A. Omer, R. Demirboga, W.H. Khushefati, Relationship between compressive strength and UPV of GGBFS based geopolymer mortars exposed to elevated temperatures, Constr. Build. Mater. 94 (2015) 189-195.

[31] A. Behnood, M. Ghandehari, Comparison of compressive and splitting tensile strength of highstrength concrete with and without polypropylene fibers heated to high temperatures, Fire Saf. J. 44 (2009) 1015-1022.

[32] B. Chen, J. Liu, Residual strength of hybrid-fiber-reinforced high-strength concrete after exposure to high temperatures, Cem. Concr. Res. 34 (2004) 1065-1069.

[33] H. Chu, J. Jiang, W. Sun, M. Zhang, Thermal behavior of siliceous and ferro-siliceous sacrificial concrete subjected to elevated temperatures, Mater. Des. 95 (2016) 470-480.

[34] M.W. Chase, NIST-JANAF Thermochemical Tables, J. Phys. Chem. Ref. Data, 1998.

[35] C. Castillo, A.J. Durrani, Effect of transient high temperature on high-strength concrete, ACI Mater. J. 87(1) (1990) 47-53.

[36] L.T. Phan, N.J. Carino, Effects of test conditions and mixture proportions on behavior of highstrength concrete exposed to high temperatures, ACI Mater. J. 99 (1) (2002) 54-66.

[37] F.J. Ulm, O. Coussy, Z.P. Bazant, The chunnel fire: chemoplastic softening in rapidly heated concrete, J. Eng. Mech. 125(3) (1999) 272-282.

[38] T. Ramanathan, A.A. Abdala, S. Stankovich, D.A. Dikin, A.M. Herrera, R.D. Piner, 
Functionalized graphene sheets for polymer nanocomposites, Nat. Nano. 3(6) (2008)327-331.

[39] P. Pliya, A.-L. Beaucour, A. Noumowe, Contribution of cocktail of polypropylene and steel fibres in improving the behaviour of high strength concrete subjected to high temperature, Constr. Build. Mater. 25 (2011) 1926-1934.

[40] M.J. Heap, Y. Lavallee, A. Laumann, K.-U. Hess, P.G. Meredith, D.B. Dingwell, S. Huismann, F. Weise, The influence of thermal-stressing (up to $1000^{\circ} \mathrm{C}$ ) on the physical, mechanical, and chemical properties of siliceous-aggregate, high-strength concrete, Constr. Build. Mater. 42 (2013) 248-265.

[41] A. Pineaud, P. Pimiedta, S. Remond, H. Carre, Mechanical properties of high performance selfcompacting concretes at room and high temperature, Constr. Build. Mater. 112 (2016) 747-755.

[42] M.-X. Xiong, J.Y.R. Liew, Mechanical behaviour of ultra-high strength concrete at elevated temperatures and fire resistance of ultra-high strength concrete filled steel tubes, Mater. Des. 104 (2016) 414-427.

[43] P. Bamonte, P.G. Gambarova, Thermal and mechanical properties at high temperature of a very high-strength durable concrete, J. Mater. Civ. Eng. 22(6) (2010) 545-555.

[44] G. Ye, X. Liu, D.-G. Schutter, Phase distribution and microstructural changes of self-compacting cement paste at elevated temperature, Cem. Concr. Res. 37(6) (2007) 978-987.

[45] Z.P. Bazant, M.F. Kaplan, Concrete at High Temperatures: Materials Properties and Mathematical Models, Longman, London, 1996.

[46] L. Zuda, R. Cerny, Measurement of linear thermal expansion coefficient of alkali-activated aluminaosilicate composites up to $1000^{\circ} \mathrm{C}$, Cem. Concr. Compos. 31(4) (2009) 263-267.

[47] T. Uygunoglu, I.B. Topcu, Thermal expansion of self-consolidating normal and lightweight aggregate concrete at elevated temperature, Constr. Build. Mater. 23 (2009) 3063-3069.

[48] A. Al-Sibahy, R. Edwards, Thermal behaviour of novel lightweight concrete at ambient and elevated temperatures: Experimental, modelling and parametric studies, Constr. Build. Mater. 31 (2012) 174-187.

[49] Z. Xing, A.-L. Beaucour, R. hebert, A. Noumowe, B. Ledesert, Influence of the nature of aggregates on the behaviour of concrete subjected elevated temperature, Cem. Concr. Res. 41 (2011) 392-402. 
Table 1 Chemical composition and physical properties of cement and supplementary cementitious materials

\begin{tabular}{|c|c|c|c|}
\hline Materials & Cement & Silica fume & Fly ash \\
\hline Chemical composition & $(w t \%)$ & & \\
\hline $\mathrm{CaO}$ & 64.70 & 0.77 & 8.38 \\
\hline $\mathrm{SiO}_{2}$ & 20.40 & 96.18 & 47.96 \\
\hline $\mathrm{Al}_{2} \mathrm{O}_{3}$ & 4.70 & 0.96 & 30.46 \\
\hline $\mathrm{Fe}_{2} \mathrm{O}_{3}$ & 3.38 & 0.85 & 5.91 \\
\hline $\mathrm{MgO}$ & 0.87 & 0.74 & 2.60 \\
\hline $\mathrm{SO}_{3}$ & 1.88 & 0.50 & 1.32 \\
\hline $\mathrm{K}_{2} \mathrm{O}$ & 0.83 & & 1.61 \\
\hline $\mathrm{Na}_{2} \mathrm{O}$ & & & 1.76 \\
\hline Loss & 3.24 & & \\
\hline \multicolumn{4}{|l|}{ Physical properties } \\
\hline Specific gravity & 3.15 & 2.22 & \\
\hline Specific surface $\left(\mathrm{m}^{2} / \mathrm{kg}\right)$ & 362.20 & $2.79 \times 10^{4}$ & \\
\hline
\end{tabular}

Table 2 Sieve analysis of silica sand (wt $\%)$

\begin{tabular}{lllllll}
\hline Particle size (mm) & $0-0.15$ & $0.15-0.30$ & $0.30-0.63$ & $0.63-2.36$ & $2.36-4.75$ & $4.75-8.00$ \\
\hline Silica sand & 6.30 & 7.60 & 13.50 & 14.60 & 11.50 & 46.50 \\
\hline
\end{tabular}


Table 3 Physical and mechanical properties of polypropylene fibre

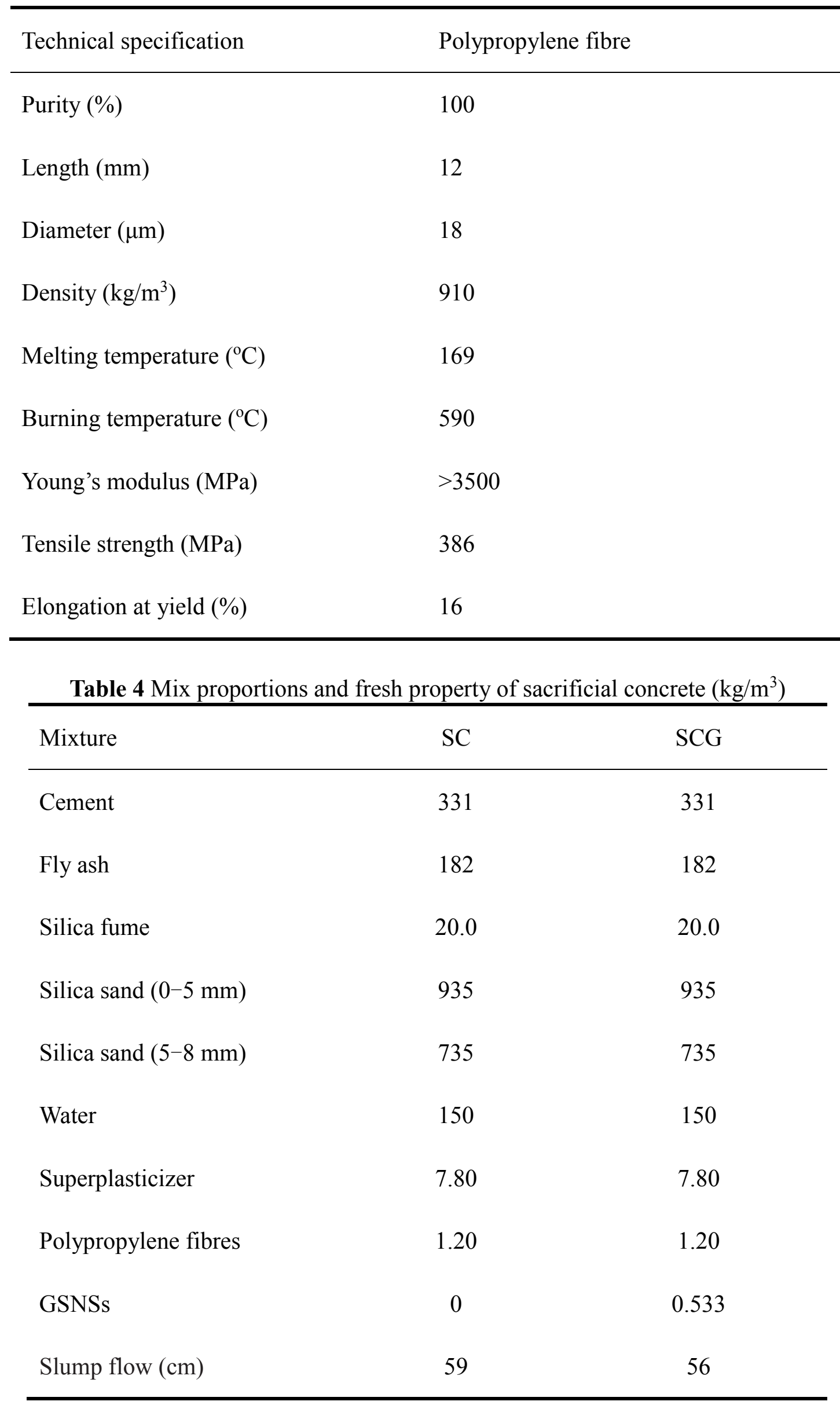


Table 5 Mass loss ratio and volumetric coefficient of thermal expansion of sacrificial concrete

\begin{tabular}{|c|c|c|c|c|}
\hline \multirow[b]{2}{*}{ Temperature $\left({ }^{\circ} \mathrm{C}\right)$} & \multicolumn{2}{|c|}{ Mass loss ratio $\left(\times 10^{-2}\right)$} & \multicolumn{2}{|c|}{ Volumetric CTE $\left(\times 10^{-5}\right)$} \\
\hline & $\mathrm{SC}$ & SCG & $\mathrm{SC}$ & SCG \\
\hline 25 & 0 & 0 & 0 & 0 \\
\hline 200 & 1.47 & 1.88 & 3.98 & 4.15 \\
\hline 400 & 2.15 & 2.60 & 5.55 & 5.41 \\
\hline 600 & 3.30 & 3.46 & 8.19 & 7.80 \\
\hline 800 & 5.01 & 4.62 & 6.23 & 5.93 \\
\hline 1000 & 5.17 & 4.86 & 5.08 & 4.75 \\
\hline
\end{tabular}

Table 6 Thermal parameters of sacrificial concrete before and during exposure to high temperatures

\begin{tabular}{|c|c|c|c|c|c|c|}
\hline \multirow{3}{*}{$\begin{array}{l}\text { Thermal } \\
\text { parameters } \\
\text { Temperature }\left({ }^{\circ} \mathrm{C}\right)\end{array}$} & \multirow{2}{*}{\multicolumn{2}{|c|}{$\begin{array}{l}\text { Thermal conductivity } \\
\qquad[\mathrm{W} /(\mathrm{m} \cdot \mathrm{K})]\end{array}$}} & \multirow{2}{*}{\multicolumn{2}{|c|}{$\begin{array}{l}\text { Specific heat } \\
{[\mathrm{J} /(\mathrm{g} \bullet \mathrm{K})]}\end{array}$}} & \multirow{2}{*}{\multicolumn{2}{|c|}{$\begin{array}{l}\text { Thermal diffusivity } \\
\qquad\left(\mathrm{mm}^{2} / \mathrm{s}\right)\end{array}$}} \\
\hline & & & & & & \\
\hline & $\mathrm{SC}$ & SCG & $\mathrm{SC}$ & SCG & $\mathrm{SC}$ & SCG \\
\hline 25 & 2.15 & 2.85 & 0.55 & 0.68 & 1.69 & 1.80 \\
\hline 200 & 1.73 & 2.27 & 0.70 & 0.84 & 1.08 & 1.18 \\
\hline 400 & 1.67 & 1.99 & 0.83 & 0.91 & 0.89 & 0.97 \\
\hline 600 & 1.16 & 1.75 & 1.10 & 1.30 & 0.47 & 0.60 \\
\hline 800 & 1.55 & 2.06 & 1.20 & 1.48 & 0.59 & 0.63 \\
\hline 1000 & 1.76 & 2.46 & 1.43 & 1.61 & 0.56 & 0.69 \\
\hline
\end{tabular}



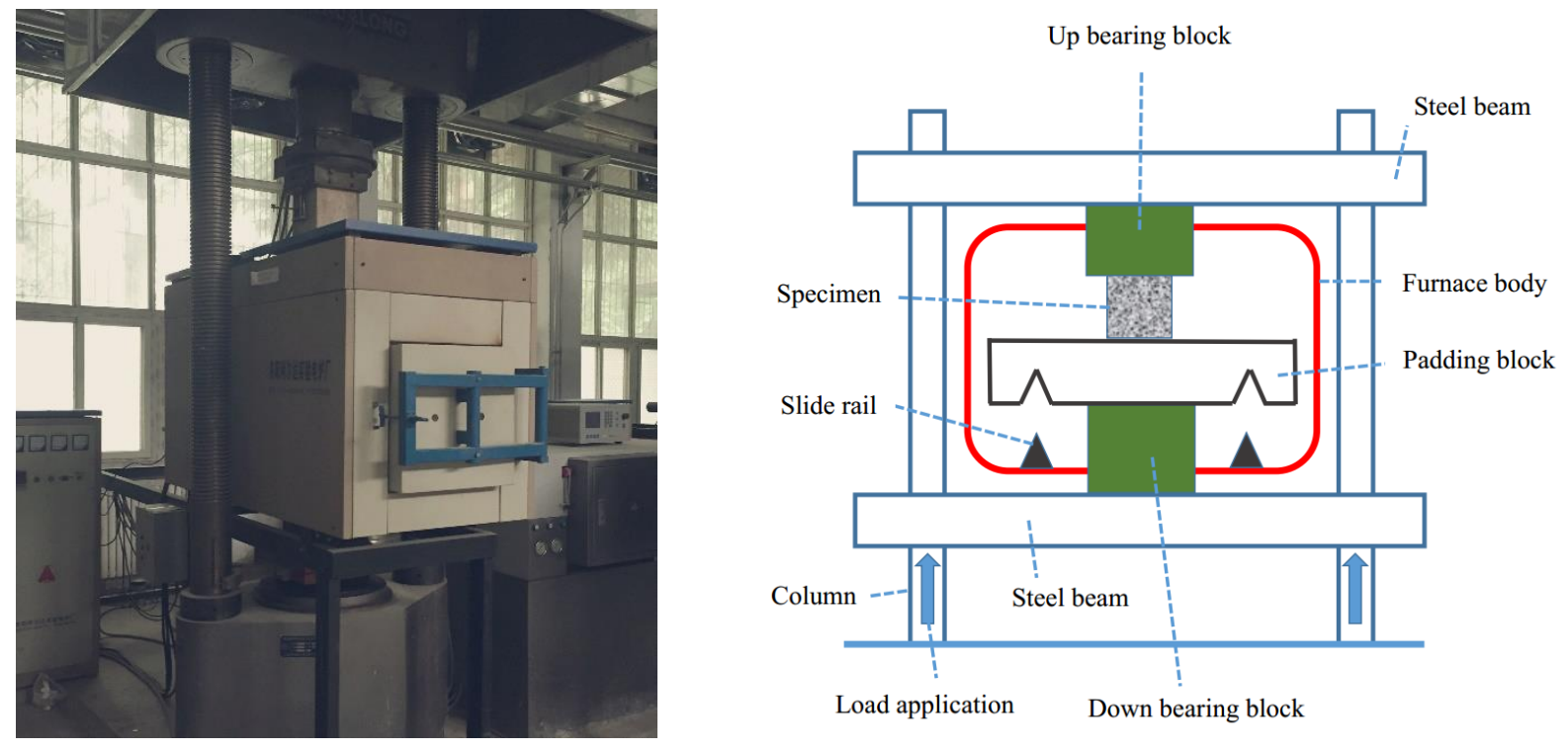

Fig.1. The new test setup for the compressive strength measurement during high temperature exposure 

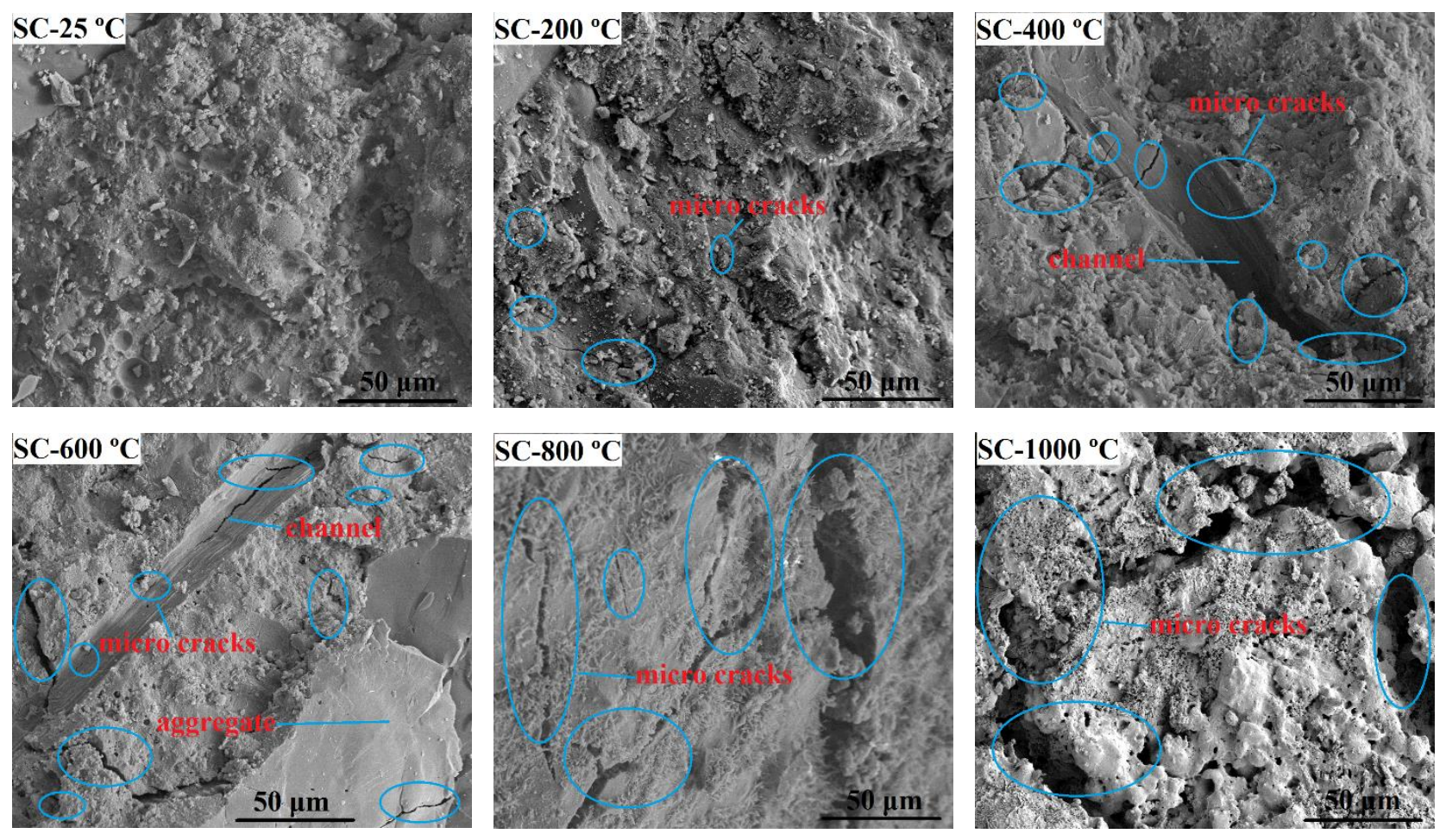

(a)
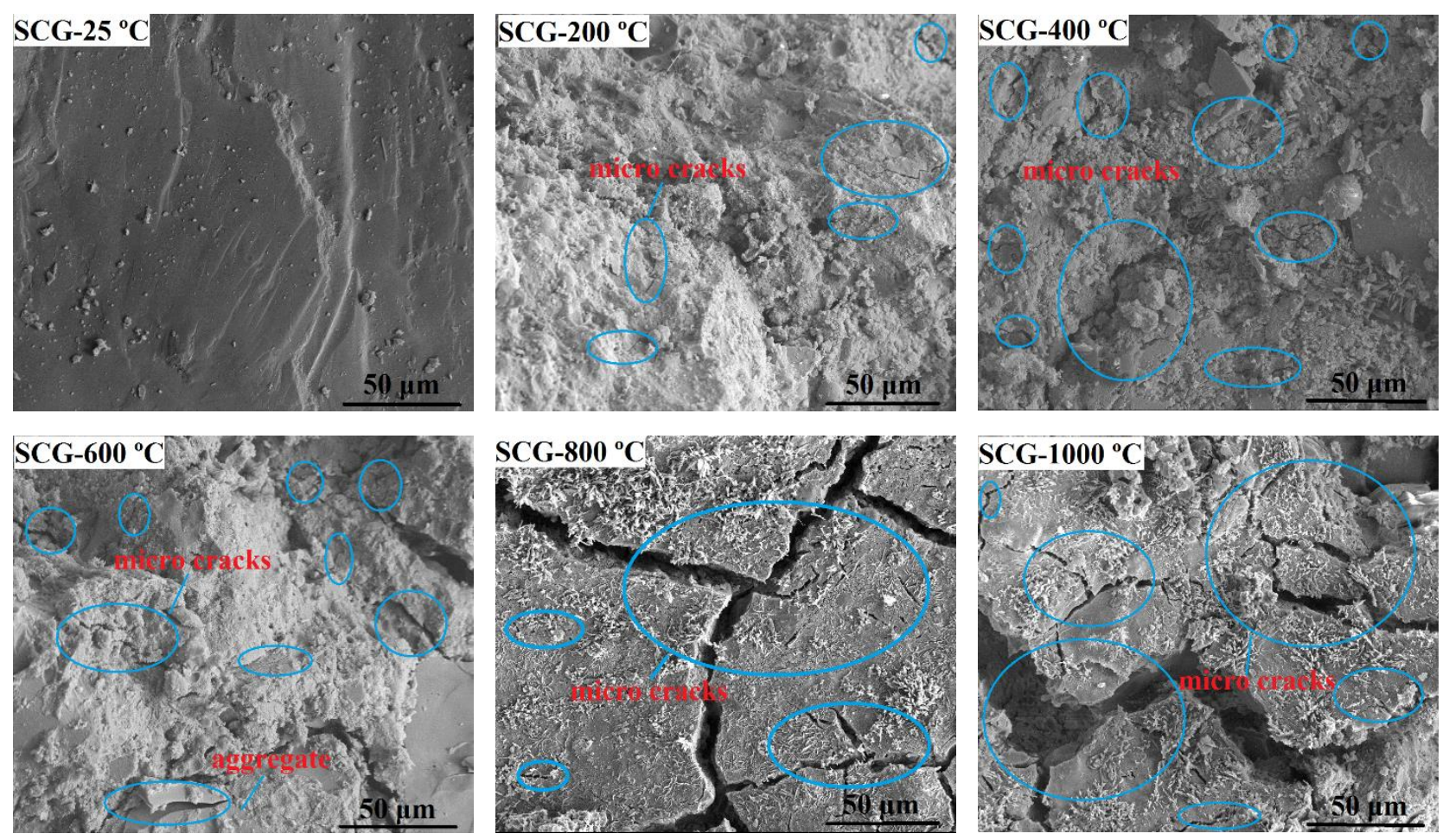

(b)

Fig.2. ESEM micrographs of specimens before and after exposure to high temperatures: (a) sacrificial concrete without GSNSs (SC) and (b) sacrificial concrete with GSNSs (SCG) 


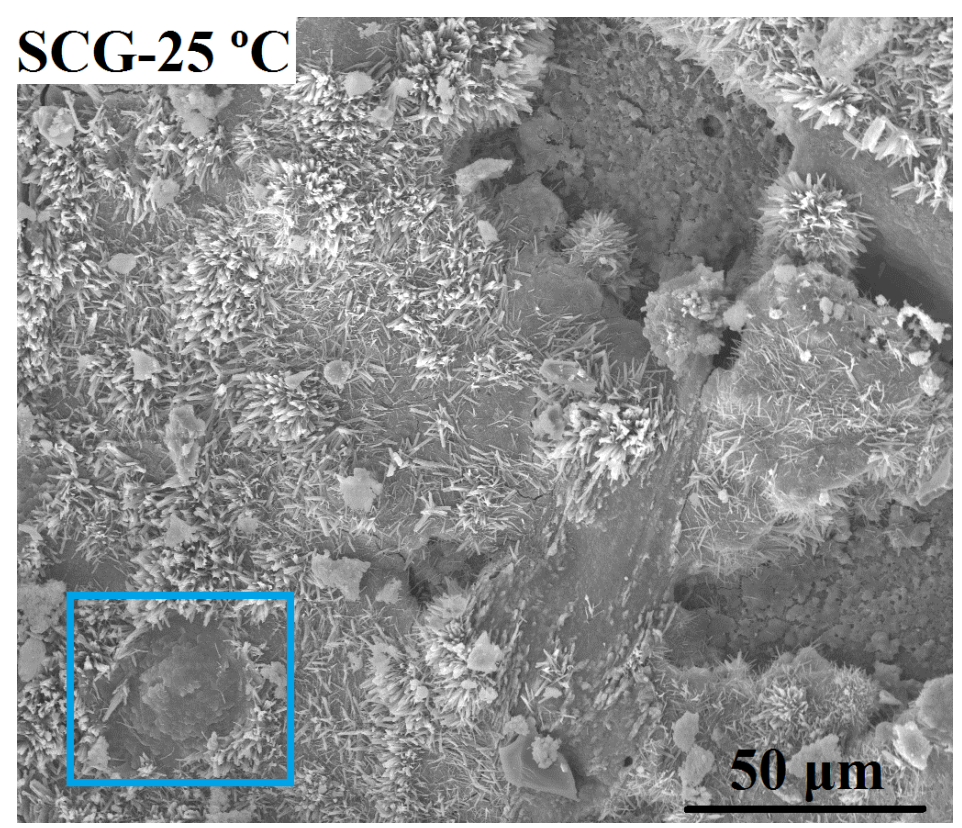

(a)

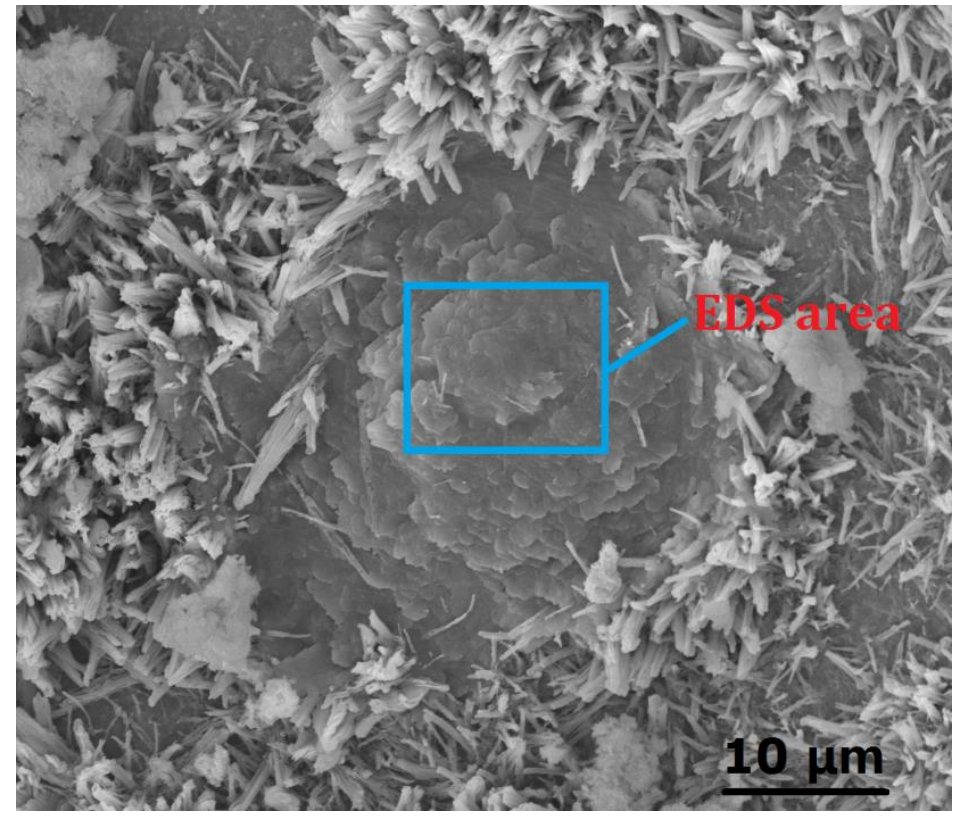

(b)

Fig.3. ESEM micrograph at a pore: (a) sacrificial concrete with GSNSs (SCG) and (b) reinforcing and toughing effects on the pore structure induced by GSNSs 


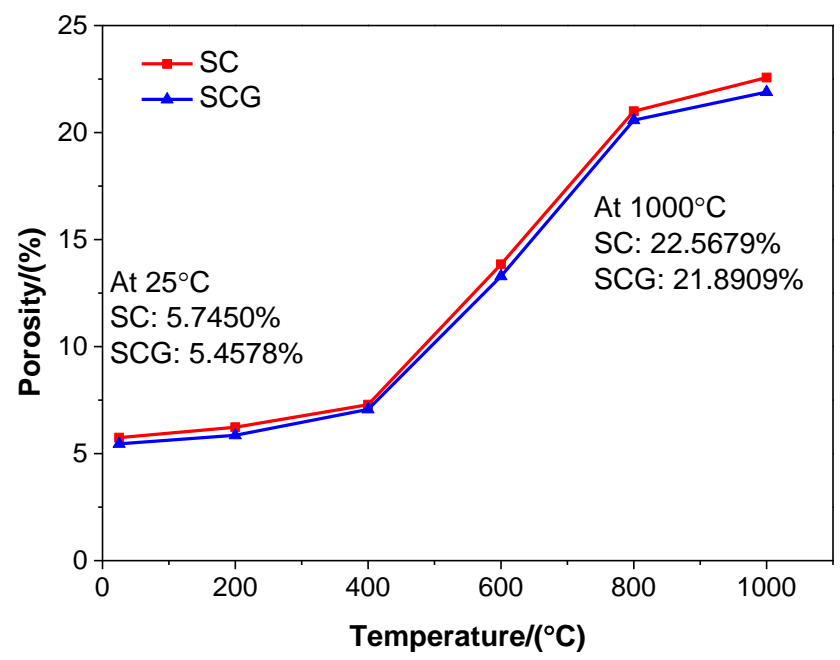

(a)

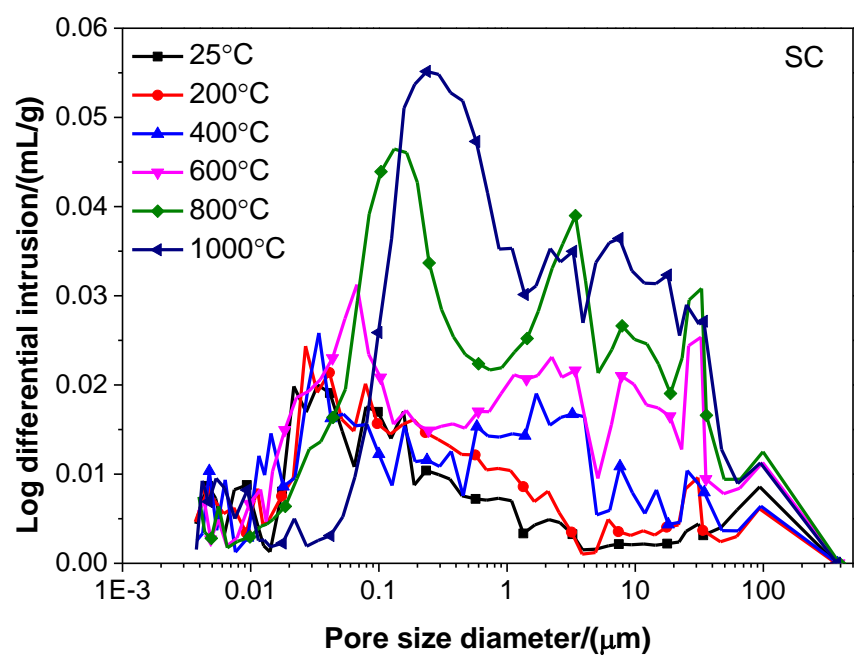

(b)

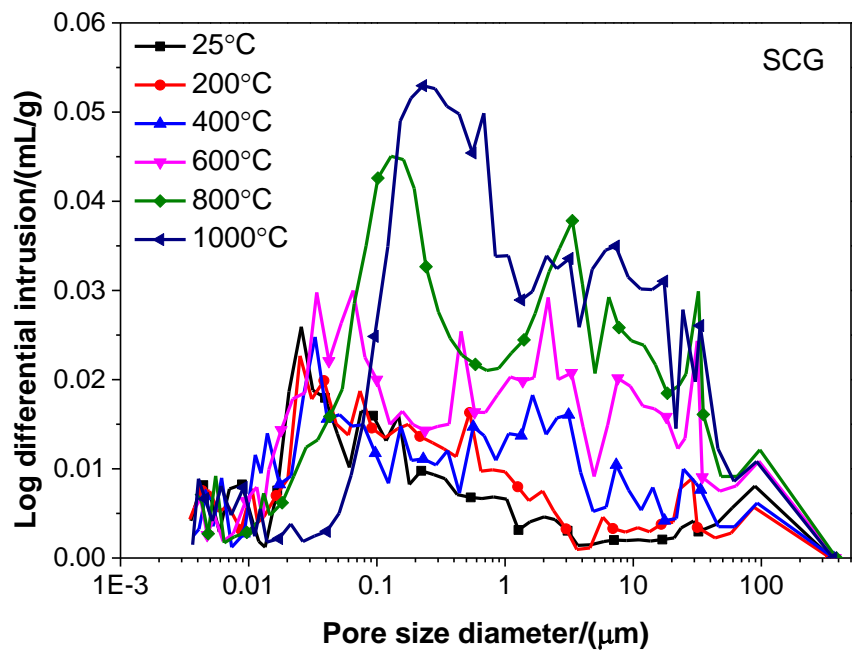

(c)

Fig.4. The porosity (a) and pore size distribution (b), and (c) of sacrificial concrete at ambient 
temperature $\left(25^{\circ} \mathrm{C}\right)$ and after exposure to $200,400,600,800$, and $1000{ }^{\circ} \mathrm{C}$

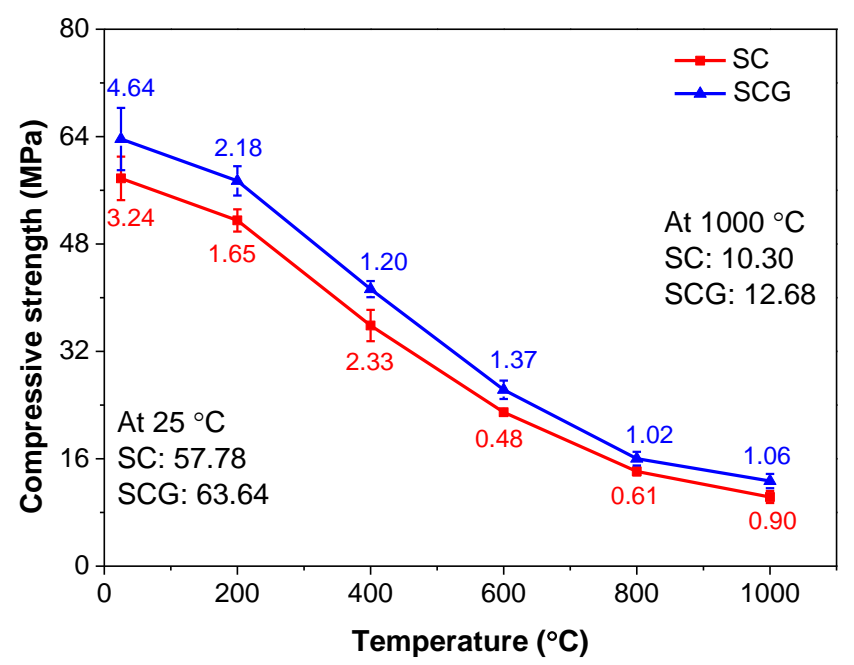

(a)

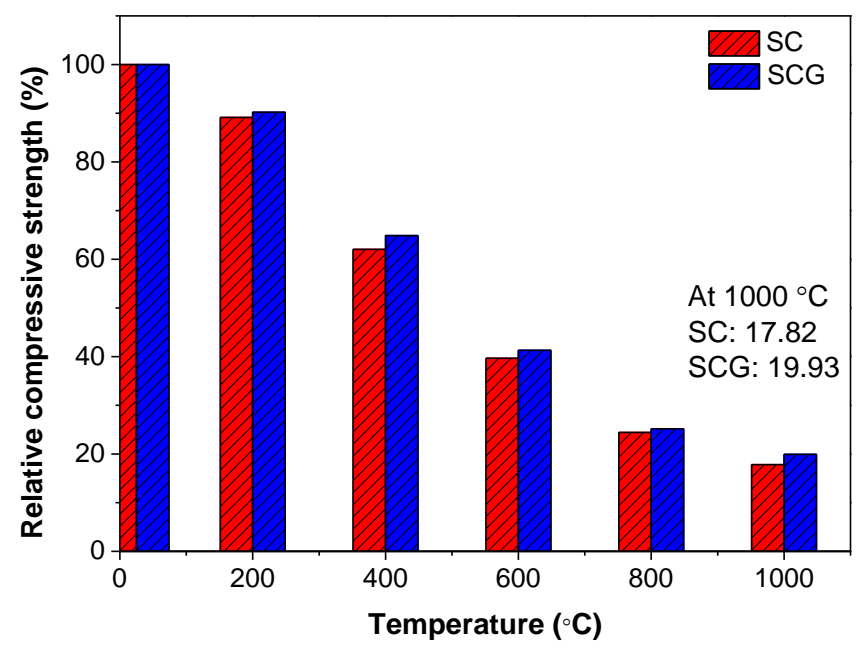

(b)

Fig.5. The strength of sacrificial concrete before and during exposure to high temperatures: (a) residual compressive strength and (b) relative residual compressive strength (compared to strength at $25^{\circ} \mathrm{C}$ ) 


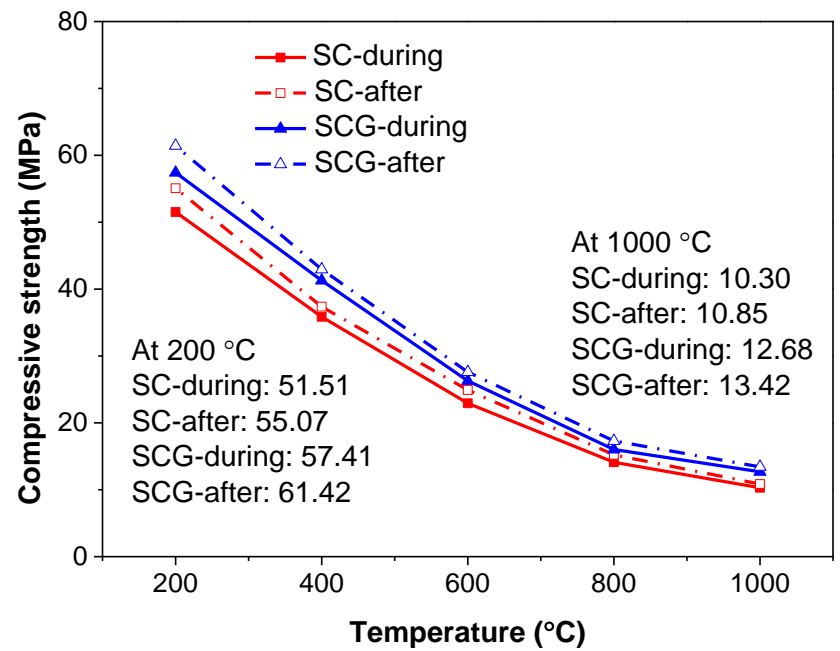

Fig.6. The compressive strength of sacrificial concrete during and after exposure to high temperatures 


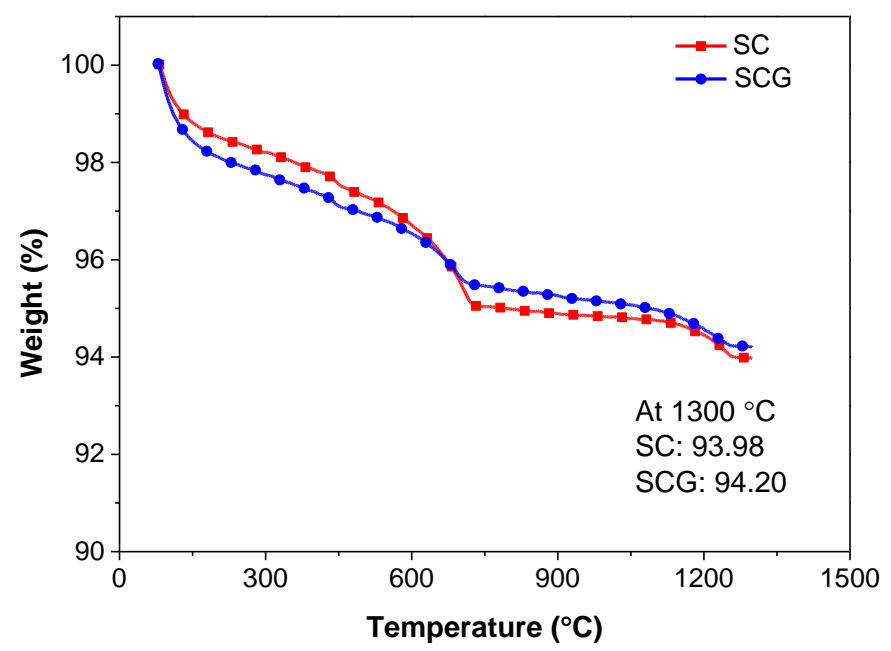

(a)

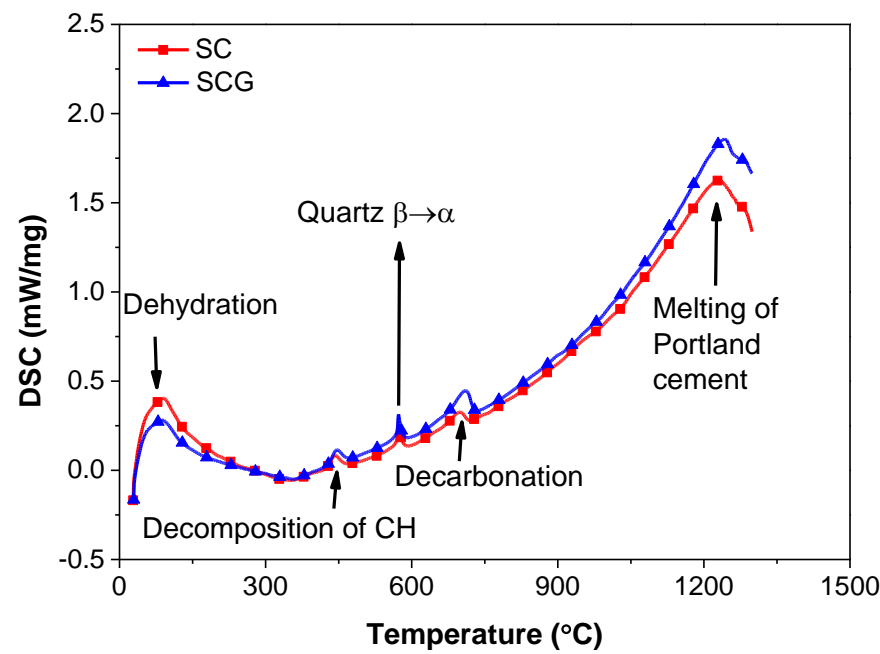

(b)

Fig.7. Thermal analysis of sacrificial concrete: (a) TGA curves and (b) DSC spectrums 


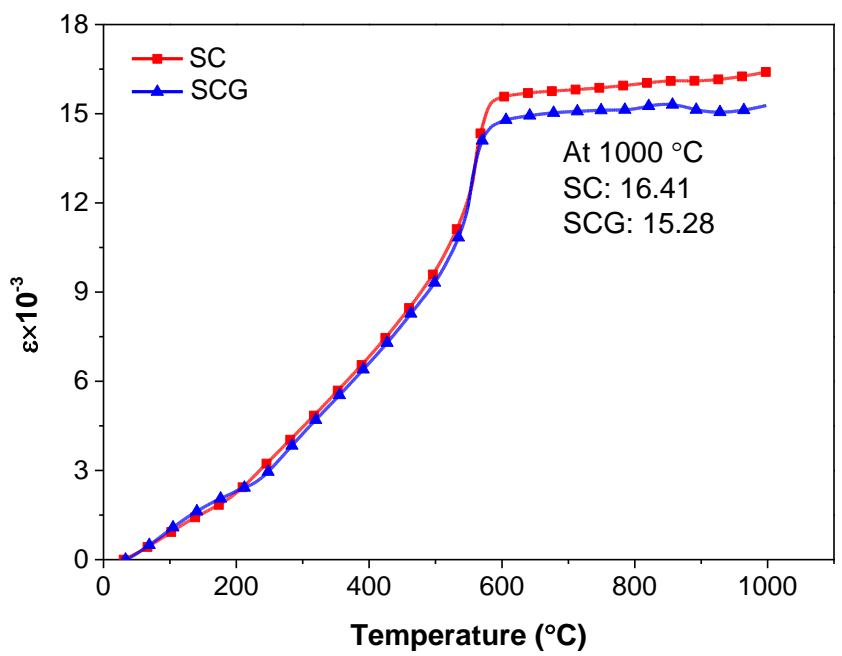

Fig.8. The thermal strain of sacrificial concrete without and with GSNSs

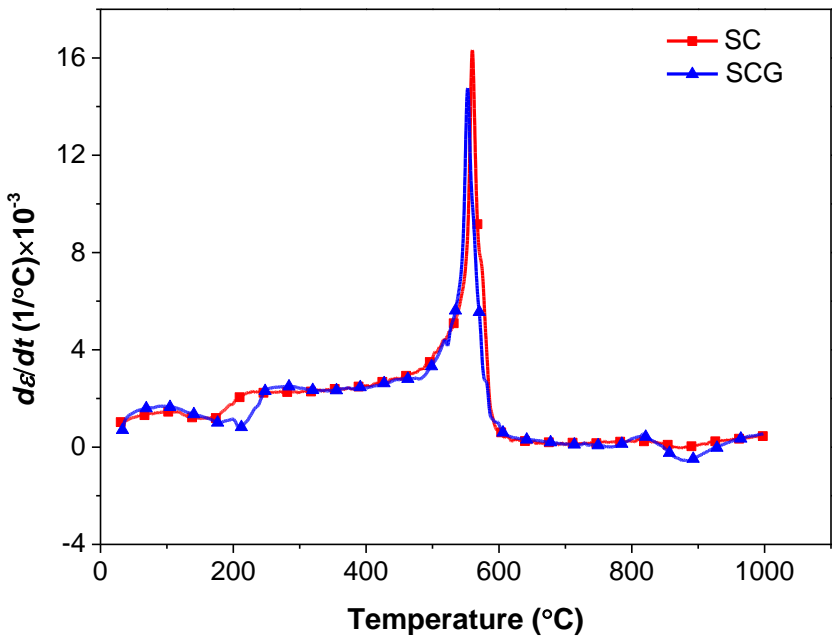

Fig.9. The first derivation of the thermal strain of sacrificial concrete 


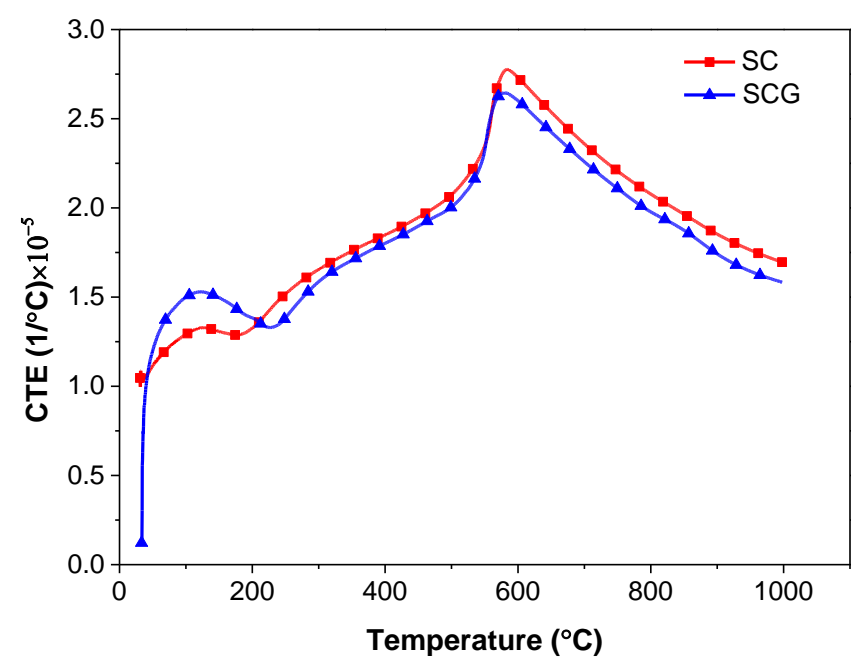

Fig.10. The CTE of sacrificial concrete without and with GSNSs

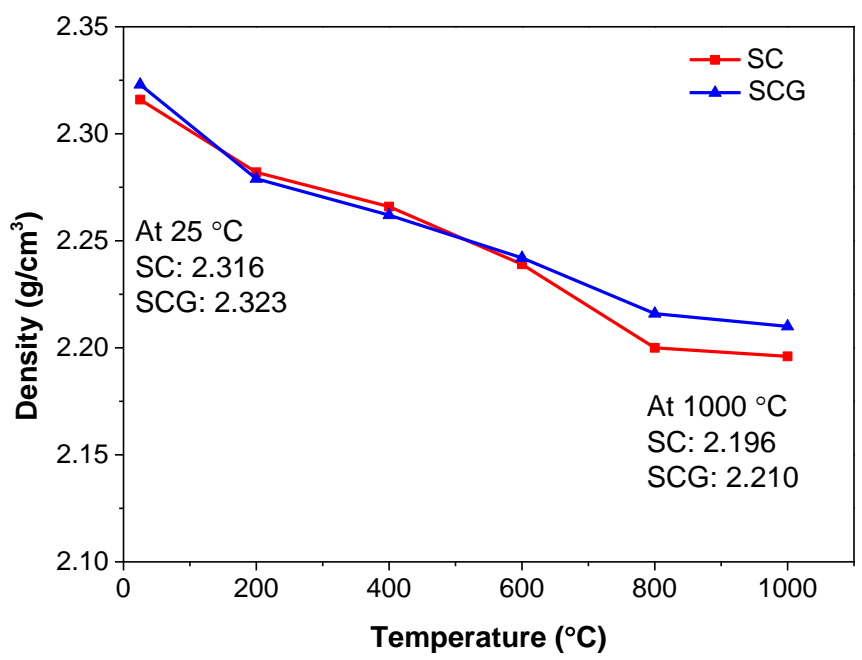

Fig.11. The density evolution of sacrificial concrete 


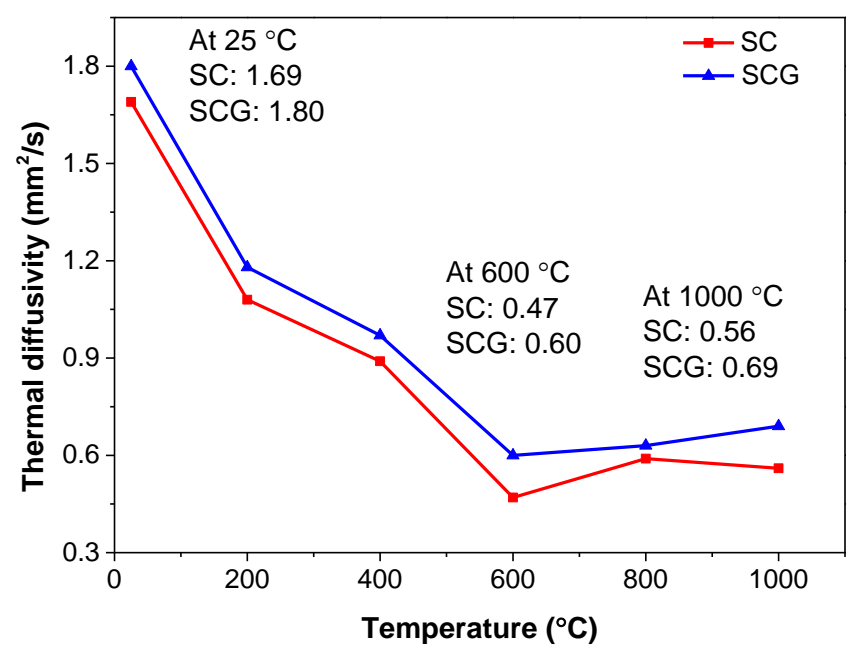

Fig.12. The thermal diffusivity of sacrificial concrete at ambient temperature $\left(25^{\circ} \mathrm{C}\right)$ and during exposure to high temperatures

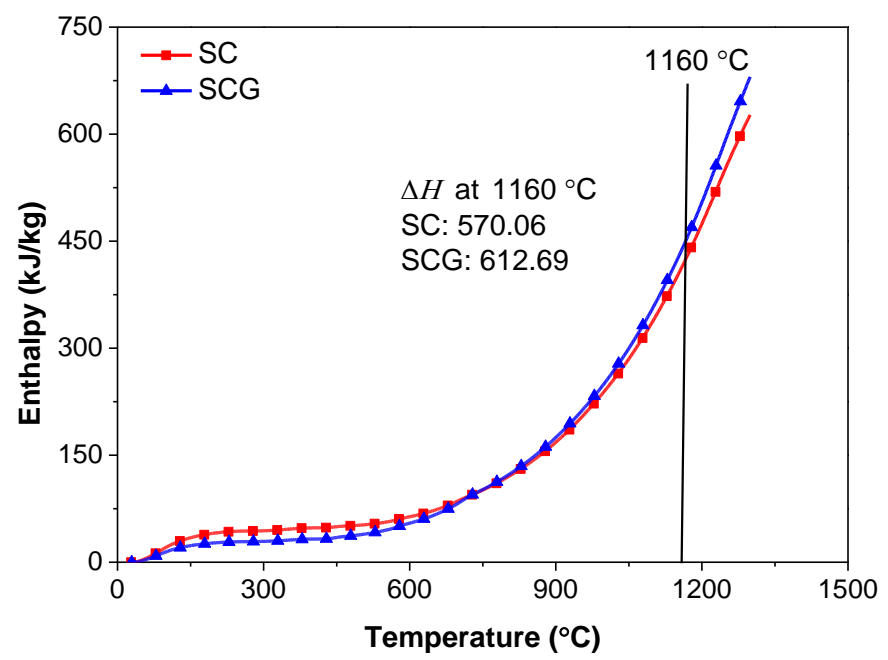

Fig.13. The enthalpy and decomposition enthalpy $\left(\right.$ at $\left.1160{ }^{\circ} \mathrm{C}\right)$ of sacrificial concrete 